Florida International University

FIU Digital Commons

FIU Electronic Theses and Dissertations

University Graduate School

$5-28-2019$

\title{
\#FOMO: How the Fear of Missing Out Drives Consumer Purchase Decisions
}

Michelle Van Solt

michelle.vansolt@valpo.edu

Follow this and additional works at: https://digitalcommons.fiu.edu/etd

Part of the Advertising and Promotion Management Commons, Education Commons, Hospitality Administration and Management Commons, Human Resources Management Commons, Marketing Commons, Psychology Commons, Recreation Business Commons, Sales and Merchandising Commons, Sociology Commons, Technology and Innovation Commons, and the Tourism and Travel Commons

\section{Recommended Citation}

Van Solt, Michelle, "\#FOMO: How the Fear of Missing Out Drives Consumer Purchase Decisions" (2019). FIU Electronic Theses and Dissertations. 4268.

https://digitalcommons.fiu.edu/etd/4268

This work is brought to you for free and open access by the University Graduate School at FIU Digital Commons. It has been accepted for inclusion in FIU Electronic Theses and Dissertations by an authorized administrator of FIU Digital Commons. For more information, please contact dcc@fiu.edu. 


\title{
FLORIDA INTERNATIONAL UNIVERSITY \\ Miami, Florida
}

\section{\#FOMO: HOW THE FEAR OF MISSING OUT DRIVES CONSUMER PURCHASE DECISIONS}

\author{
A dissertation submitted in partial fulfillment of \\ the requirements for the degree of \\ DOCTOR OF PHILOSOPHY \\ in \\ BUSINESS ADMINISTRATION
}

by Michelle Van Solt 


\section{To: Dean Joanne Li \\ College of Business}

This dissertation, written by Michelle Van Solt, and entitled \#FOMO: How the Fear of Missing Out Drives Consumer Purchase Decisions, having been approved in respect to style and intellectual content, is referred to you for judgment.

We have read this dissertation and recommend that it be approved.

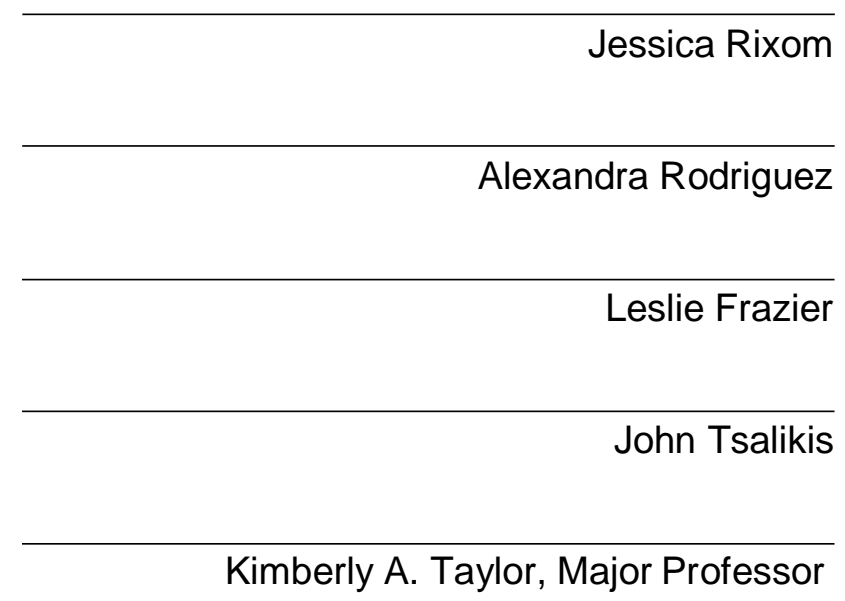

Date of Defense: May 28, 2019

The dissertation of Michelle Van Solt is approved.

Dean Joanne Li
College of Business

Florida International University, 2019 
(C) Copyright 2019 by Michelle Van Solt

All rights reserved. 


\section{DEDICATION}

I dedicate this dissertation to my husband, Christian Caporaletti, who supported me every day of this journey with so much patience, love, and strength. I am forever grateful. 


\section{ACKNOWLEDGMENTS}

This work would not have been possible without the constant support of Dr. Kimberly Taylor and Dr. Jessica Rixom. In particular, Dr. Rixom's early interest in my work encouraged me to pursue FOMO as my dissertation topic, and since then her kind and meticulous feedback greatly contributed to the successful completion of this work. I wish to thank my committee members Dr. Alexandra Rodriguez-Aguirre, Dr. John Tsalikis, and Dr. Leslie Frazier for their constant encouragement and insightful comments. All of their feedback and direction have been immensely helpful. I would like to thank Dr. Tsalikis for having confidence in my abilities and providing me with opportunities to grow as a researcher.

I would like to thank my parents, Yemile and Robert Van Solt, whose love and guidance are with me in whatever I pursue. I am also grateful to my siblings Arianne, Bryan, Patricia, my godfather Rostislav Ordovsky-Tanaevsky, and all of my friends for their understanding and support in my path for academic growth. I would not have been able to accomplish this without my colleague, Tessa Garcia-Collart, whose friendship, support, and humor made all of the difference in the world.

Most importantly, I would like to express my most sincere gratitude to my dissertation chair, Dr. Taylor. Her constant faith in me, guidance, and incredible generosity provided me with the tools I needed to reach my biggest academic achievement yet. 


\title{
ABSTRACT OF THE DISSERTATION
}

\#FOMO: HOW THE FEAR OF MISSING OUT DRIVES CONSUMER

PURCHASE DECISIONS

\author{
by \\ Michelle Van Solt \\ Florida International University \\ Miami, Florida \\ Professor Kimberly A. Taylor, Major Professor
}

This research focuses on consumers' experiential purchase decisions motivated by the fear of missing out (FOMO). I propose that consumers are more likely to attend an event when individuals with whom they have strong (weak) interpersonal ties will be present, because consumers will experience higher (lower) levels of FOMO. The results of one qualitative and four quantitative studies, including a behavioral study, demonstrate that purchase intent is higher when participants imagine that their close friends (i.e., strong ties) will attend, an effect mediated by FOMO and anticipated regret. Furthermore, the type of experience (i.e., ordinary, extraordinary) moderates the relationship of social ties (strong, weak) on FOMO and anticipated regret. This serial moderated mediation model indicates that the social group has no effect when an experience is extraordinary but does when an experience is ordinary.

This dissertation also highlights the distinctions between the constructs of FOMO and anticipated regret. These findings provide evidence of the circumstances that can result in greater feelings of $\mathrm{FOMO}$, and consequently, in increased purchase intent. Other constructs such as social exclusion are discussed. I also observe whether FOMO is an automatic process or if it is experienced after careful consideration of the stimuli. 
This is the first empirical research, to my knowledge, to consider purchase and behavioral intent as a consequence of FOMO. The data collected and analyzed support most of the hypotheses including that FOMO is experienced more commonly with strong ties as opposed to weak ties, that FOMO and anticipated regret are serial mediators to the relationship between social ties and purchase intent, and that this relationship is moderated by the type of experience (although experienced equally during an extraordinary experience for both strong and weak social ties), and that FOMO is an automatic phenomenon. FOMO had been commonly studied previously as an individual difference, but here I investigate situational circumstances that result in higher levels of FOMO for the general consumer population. Future research on this topic is encouraged to explore other consequences and ramifications of FOMO and how it affects consumers. 
CHAPTER

PAGE

I. INTRODUCTION

II. CONCEPTUAL BACKGROUND

2.1 Origins of $\mathrm{FOMO} \quad 6$

$\begin{array}{lll}2.2 & \text { Definitions } & 7\end{array}$

$\begin{array}{lll}2.3 & \text { Examples of FOMO } & 10\end{array}$

$\begin{array}{lll}2.4 & \text { FOMO and technology } & 11\end{array}$

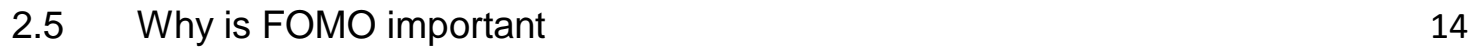

2.5.1 Anticipated FOMO and consumer decisions 14

$\begin{array}{ll}\text { 2.5.2 FOMO advertising appeals } & 14\end{array}$

2.5.3 Negative implications of FOMO 16

$\begin{array}{ll}\text { 2.5.4 Positive implications } & 17\end{array}$

III. LITERATURE REVIEW ON FOMO 20

3.1 Theory of motivation and FOMO 21

3.2 Antecedents of FOMO 22

3.3 Consequences of FOMO 23

IV. FOMO AS A SOCIAL CONSTRUCT 25

$\begin{array}{lll}4.1 & \text { Introduction } & 26\end{array}$

4.2 Tie Strength Theory 26

$\begin{array}{ll}4.2 .1 \text { Definition } & 27\end{array}$

4.2.2 Strong ties 28

4.2.3 Weak ties (the strength of weak ties) 29

4.2.4 FOMO and tie strength $\quad 29$

$\begin{array}{ll}4.3 \text { Social exclusion } & 30\end{array}$

V. FOMO AND REGRET 32

5.1 FOMO vs. Regret 33

5.2 Social nature 33

$\begin{array}{lll}5.3 & \text { Choice element } & 34\end{array}$

$\begin{array}{lll}5.4 & \text { Responsibility element } & 36\end{array}$

VI. FOMO AND EXPERIENTIAL CONSUMPTION 38

6.1 Consumption of experiences 39

6.2 Social Experiences 40

6.3 Ordinary experiences 41

6.4 Extraordinary experiences 41

6.5 Connection between FOMO and PI 42

VII. AUTOMATICITY

$\begin{array}{lll}7.1 & \text { Introduction } & 45\end{array}$ 
$\begin{array}{lll}7.2 & \text { Conscious versus unconscious } & 46\end{array}$

7.3 Efficient versus inefficient 46

$7.4 \quad$ Intentional versus unintentional $\quad 47$

7.5 Controllable versus uncontrollable $\quad 47$

VIII. RESEARCH PLAN \& HYPOTHESES

8.1 Theoretical Framework 50

8.2 Hypotheses 51

8.3 Overview of studies 54

IX. STUDY 1 - FOCUS GROUPS

9.1 Methodology $\quad 57$

9.2 Results 58

$\begin{array}{lll}9.3 & \text { Mind map } & 61\end{array}$

X. STUDY 2 - SERIAL MEDIATION 63

10.1 Introduction

10.2 Methodology 64

10.3 Results 65

10.4 Discussion 68

XI. STUDY 3 - SERIAL MODERATED MEDIATION 69

$\begin{array}{lll}11.1 & \text { Introduction } & 70\end{array}$

$\begin{array}{lll}11.2 & \text { Methodology } & 71\end{array}$

11.3 Results $\quad 72$

11.4 Discussion $\quad 77$

XII. STUDY 4 - AUTOMATICITY

12.1 Introduction 80

12.2 Methodology 80

12.3 Results 82

12.4 Discussion 83

XIII. STUDY 5 - BEHAVIORAL STUDY 84

13.1 Introduction $\quad 85$

13.2 Methodology 85

13.3 Pretest results 88

13.4 Main study results 88

13.5 Discussion 89

XIV. CONCLUSION 91

14.1 Extended discussion 92

14.2 Practical implications for marketers 92

14.3 Limitations 96 
14.4 Future directions

REFERENCES

99

APPENDIX

110

VITA

117 


\section{LIST OF FIGURES}

FIGURE

PAGE

1. Tuborg' 2014 global campaign focused on appeasing FOMO

2. Fashion store, FOREVER21

3. Conceptual model (serial moderated mediation)

$\begin{array}{ll}\text { 4. Mind map } & 63\end{array}$

$\begin{array}{ll}\text { 5. Serial mediation results } & 67\end{array}$

6. FOMO and anticipated regret as dependent variables 74

7. Serial moderated mediation results 75 
CHAPTER I. INTRODUCTION 
"One recent rainy night, I curled up on my couch with popcorn and Netflix Instant, ready to spend a quiet night at home. The peace was sweet while it lasted. Soon, my iPhone began flashing with notifications from a handful of social networking sites, each a beacon of information about what my friends were doing.

As the alerts came in, my mind began to race. Three friends, I learned, had arrived at a music venue near my apartment. But why? What was happening there? Then I saw pictures of other friends enjoying fancy milkshakes at a trendy restaurant. Suddenly, my simple domestic pleasures paled in comparison with the things I could be doing.

The flurry of possibilities set off a rush of restlessness and indecision. I was torn between nesting in my cozy roost or rallying for an impromptu rendezvous, and I just didn't know what to do." (Wortham, April 9 2011).

In the interconnected society in which we live, we are perpetually exposed to the whereabouts and activities of others. Through a quick check of one's phone or a glance at one's social media feed, consumers are now privy to information that may result in what modern culture terms: FOMO or the fear of missing out. FOMO is driven by a concern that friends or others are having rewarding experiences from which one is absent (Przybylski, Murayama, DeHaan, \& Gladwell, 2013; Riordan, Flett, Hunter, Scarf, \& Conner, 2015). One survey found that nearly three quarters of millennials self-reported experiencing unease when they felt like they were missing out on what their peers were doing (JWT Worldwide, 2011).

Today, FOMO is widely recognized in popular press (Hodkinson, 2016), and it was officially added to the Oxford English Dictionary in 2013. Firms also recognize the value of FOMO and use it in advertising (Hodkinson, 2016). As stated in the press: "By now, marketers who aren't embracing the power of FOMO are truly behind the times" (Cassinelli, March 20, 2017).

Characterized by a need to stay continuously connected to what others are doing (Przybylski et al., 2013), FOMO captures one of the most important concerns of the digital age: the fear that our friends are having more fun and living better lives than we 
are (Cassinelli, March 20, 2017). It has been referred to as a "modern take on the grass being greener on the other side" (Psychologies, 2012). FOMO is known to be fueled by social media posts (Przybylski et al., 2013). Many researchers believe that FOMO is not a new emotion (Abel, Buff, and Burr, 2016; Hodkidson, 2016); it simply became more salient and experienced more commonly through the rise of a social media-driven culture. Most of the academic work on this topic focuses on the individual differences that lead to FOMO and its consequences and can be found in the psychology, education, and technology literatures with hardly any empirical work in consumer behavior. The current research is situated in the consumer domain and investigates some of the antecedents of FOMO from a situational perspective.

While some individuals may be more sensitive to the effects of FOMO (Przybylski et al., 2013), I suggest that there are general circumstances that can heighten the effects of this phenomenon for most consumers. More specifically, I explore the situational factors that result in higher levels of FOMO for consumers, thereby addressing issues such as which social groups are capable of instilling more FOMO in individuals and which type of experiences result in higher levels of FOMO. I believe that FOMO will be higher for consumers when one's strong rather than weak social ties are involved in a social activity and when the occasion is extraordinary rather than ordinary. I further propose that when both conditions are present, consumers will experience high levels of FOMO.

Pertinent to our research is also to determine whether FOMO is an automatic process or a nonautomatic process. More specifically, I want to distinguish if individuals carefully consider experiencing FOMO or whether it happens organically without careful thought. I also highlight the differences and commonalities between FOMO from anticipated regret. This is the first paper of which I am aware to explore anticipated or 
future FOMO, yet a popular question that comes to mind when discussing the topic is whether this is the same as regret. I make this distinction by stressing the social nature attached to FOMO that is not pertinent to anticipated regret. While I believe FOMO and regret to be distinct constructs, I posit that FOMO is an antecedent to regret and that together they can lead to increased purchase intent depending on the social group that is attending an event. I also delve into the social exclusion literatures to see whether there are any theoretical connections to FOMO.

Given that FOMO has been linked to important consequences such as feelings of loneliness (Dossey, 2014), distracted driving and decreased wellbeing (Przybylski et al., 2013), it is important to clearly identify FOMO's antecedents in order to further understand this phenomenon. In addition to proposing possible antecedents to FOMO, I propose new consequences to FOMO: purchase and behavior intent to attend an event. I suggest that FOMO can motivate people to use their resources of time and money in order to attend events or engage in experiences they may not attend otherwise.

The rest of this dissertation proceeds as follows. I begin by reviewing the antecedents to and consequences of FOMO that have been identified in prior literature including psychology and education. These serve as the basis for my predictions regarding the impact of social groups and type of experience on FOMO. I then explore the connection between FOMO and others through the tie strength literature to illustrate the construct's social nature. I further explore experience type as I propose new antecedents to FOMO. I finally conclude the literature review by differentiating FOMO from anticipated regret and highlighting how together they can affect consumer behavior. Five studies - a qualitative focus group and four quantitative studies (including a behavioral study) - test my hypotheses regarding social ties and experience type leading to FOMO. Finally, I discuss theoretical and practical implications of this research. 
CHAPTER II. CONCEPTUAL BACKGROUND 


\subsection{Origins of $\mathrm{FOMO}$}

The exact origins of the term FOMO are a bit unclear (Hodkinson, 2016). The phrase 'fear of missing out' was first identified in the academic literature in 2000 in the Journal of Brand Management (Herman, 2000), but it was not seen again until 2010 (Voboril, 2010). The first mention of the fear of missing out was in relation to consumers' shift from using long-term brands (i.e., brands that are trustworthy) to trying new things, or short- term brands (i.e., brands that are exciting), given the plethora of choices (Herman, n.d.). Herman (2000) described the 'turn of the century consumer' in this manner: "The emerging portrait is of a person and consumer who is led by a new basic motivation: ambition to exhaust all possibilities and the fear of missing out on something" (p. 330).

It was not until 2004, however, that the acronym FOMO appears in press at the Harvard magazine, The Harbus. The article, written by a Harvard Business School student named Patrick McGinnis, talks about a social framework that tries to explain the social dilemma plaguing students' lives: how much social interaction is the right amount in college? In this framework, FOMO is at one end of the spectrum ruled by not wanting to miss out on anything, while the fear of a better option (FOBO) discourages students from committing to anything in particular just in case a better option comes along. While FOBO never took off the way FOMO did, the manner in which FOMO has been studied reflects aspects of FOBO as well. It is not clear whether McGinnis (2004) coined this acronym himself from a popular phrase at Harvard Business School (HSB); however, in an interview conducted by JWT Worldwide, the interviewee, Priya Parker, reveals first hearing of FOMO in 2008 at a graduate student orientation at HSB. The orientation speaker warned students that the biggest problem that they would encounter in the next 
couple of years is FOMO (Vaughn, 2012). This leads me to believe that the origins of the phrase and acronym may have originated at Harvard.

\subsection{Definitions}

Specific definitions of FOMO are limited in the literature (Hodkinson, 2016). The most commonly used definition of FOMO derives from Przybylski et al. (2013), which defines FOMO as "a pervasive apprehension that others may be having rewarding experiences from which one is absent... characterized by the desire to stay continually connected with what others are doing" (p. 1841). J. Walter Thompson (JWT) Worldwide, a well-known marketing communications brand, (2011, p. 4) defines FOMO as "the uneasy and sometimes all-consuming feeling that you're missing out - that your peers are doing, in the know about, or in possession of more or something better than you." Both of these definitions of FOMO describe a feeling of "lacking something" that is caused by comparing one's current state with that of others. Potentially, one could be doing or could have done, what other people are showing that they are currently doing or have done (through social media); however, due to lack of time, financial resources, or information, they are not doing those things which leads them to feel like they are missing out.

FOMO has also been identified as a source of social anxiety driven by a concern one might miss an opportunity for social interaction, a novel experience, or some other satisfying event often resulting from social media engagement (Dossey, 2014). In the education literature, FOMO has been seen as "a social construct that examines whether students are concerned that they are missing out on experiences that others are having" (Hertz, Dawson, and Cullen, 2015, p. 259). Others believe that FOMO is associated with the fundamental need to belong (Baumeister \& Leary, 1995; Nadkarn \& Hofmann 2012; Seidman 2013), a basic human motivation defined as the desire for interpersonal 
attachments that can be stalled by social exclusion. Although academic research points out that FOMO has more to do with social inclusive behavior than social exclusive behavior (Lai, Altavilla, Ronconi, \& Aceto 2016), industry research views FOMO as being related to social exclusion and explores FOMO with such metrics (Abel et al., 2016; Vaughn, 2012). For instance, in a study done by JWT Singapore, $72 \%$ of working adults self-reported feeling left out in the real world if they do not get a chance to check their social media accounts (Vaughn, 2012).

According to Priya Parker (Vaughn, 2012), who does research with millennials, "FOMO is becoming a way of life" (para. 2). Although Parker agrees that FOMO is "particularly focused on the social landscape and fueled by technology," (para. 6) she believes that it also affects people's way of life by influencing career choices and even choices of romantic partners. Parker believes that for individuals who want to be engaged citizens, FOMO is not only about missing out on experiences but also about missing out on the latest news (Vaughn, 2012). FOMO has predicted the pace at which individuals watch TV and whether they engage in watching one-time programs like the Super Bowl (Averset, Billings, \& Conlin, 2016). This supports Parker's claim that people don't want to miss out on being in the know about current events. For instance, sporting events such as the Super Bowl provide ample topic of conversation with others, even if it's just about the commercials.

Another stream of research proposes that FOMO is comprised of irritability, anxiety and feelings of inadequacy, intensifying through social media engagement (Abel et al., 2016; Vaughn, 2012; Wortham, 2011). They see FOMO as being directly related to lower self-esteem due to feelings of inadequacy. This particular stream of research focusses solely on social media and offers limited insights on the social nature of FOMO. 
Furthermore, FOMO is a feeling that can be experienced before, during, or after an event. In one qualitative study in which participants were asked several questions regarding $\mathrm{FOMO}, 54 \%$ of participants reported usually experiencing the most FOMO during an event, 33\% stated feeling more FOMO after an event, and 22\% said they tended to experience more FOMO before an event (Rifkin, Chan, \& Kahn, 2015).

I also see appeals to FOMO being used more frequently in advertising. Hodkinson (2016) qualitatively investigates consumers' responses to ad appeals using FOMO. He defines commercial FOMO appeals as "any initiating appeal, whether in person or impersonal, originating from an organization, in which FOMO or 'missing out' is mentioned or specifically implied and the context of which is the stimulation of demand, usage or purchase of a product" (p. 67). According to Hodkinson, temporal appeals and appeals mentioning the phrase "missing out" have been part of personal selling tactics for a long time.

It is my intuition that this feeling is not literally real fear, mainly because its valence is not as negative as one would experience from an actual fear. I believe that a more accurate definition would be the "concern of missing out;" however, as FOMO is not an academic term and originated in modern popular culture, the phrase itself caught on because of its catchy and whimsical nature. According to Hodkinson (2016), the term FOMO became popular through a meme that was used in a playful and somewhat belittling way. The reality is that "people tend to use FOMO in a slightly ironic manner: 'Oh, I'm suffering from so much FOMO,' and everyone's natural reaction is to laugh" (Vaughn, 2012; para. 10).

Past research on FOMO primarily has studied the construct from an individual difference perspective, almost as a personality trait (Al-Menayes 2016; Baker, Krieger, and LeRoy, 2016; Collins \& Van Abeele, 2013; Hato, 2013; Hodkinson, 2016; Przybylski 
2013; Riordan et al. 2015) and the situational antecedents to FOMO have been largely overlooked. In contrast, Parker (Vaughn, 2012) believes that FOMO is a shared experience that we all suffer from, making it "almost impossible not to feel FOMO unless you're wearing blinders" (para. 31).

\subsection{Examples of $\mathrm{FOMO}$}

Because time is a limited resource and the plethora of options available today are made salient through constant connectivity, people are inevitably going to miss out on some things (Przybylski et al., 2013). This excess of information and availability of options makes people worry or hesitate when making decisions and commitments due to the possibility of a better option presenting itself (Vaughn, 2012). For instance, deciding which event to attend when two or more events will take place at the same time, or even choosing to not attend any event, may lead one to experience FOMO. As one cannot be in two places at once and time is a limited resource, consumers are forced to make regular decisions on which events to attend and which to skip.

Social media, particularly, has digitally connected people to the extent that we are always aware of all the social activities that we could be doing (Przybylski et al., 2013). Fifteen years ago, one may have seen details about a close friend's Hawaiian vacation a good two weeks after it happened by paying a personal visit to their home to spend the afternoon flipping through a picture album and seeing physically developed images of them standing on a sandy beach. Today, we have both the luxury and the misfortune of being able to see everyone's trips, family gatherings, walks with their dogs, and the food they consume at any time simply by going through our phones (provided it is posted on social media). Whether one wants to see where Fred from human resources went during his time off or not, the vastness of information of what others are doing may act as a mirror of possibilities to the interesting things one could potentially be 
doing. It can also lead people to feel FOMO even when they would much prefer to use their limited time to rest or work. As expressed in a happiness blog:

"I used to push myself to do things that I maybe didn't really want to do because of FOMO. I would go places and do things that my inner being knew I didn't really need to do because of FOMO. What if something fun happened and I wasn't there?" (The Sattvic, 2015; para. 2).

The person in the example above has expressed experiencing FOMO on a regular basis for a period of time. As a person succumbs to the feeling of FOMO, "the energy needed to maintain such an active social life is tremendous" (The Harbus, 2004). While FOMO can be a motivator to engage in social activities that can lead to positive outcomes like making friends (University of Southern Queensland, 2017), too much FOMO can lead individuals to feel depleted or spread too thinly. In line with the above quote, the FOMO literature posits that when a person experiences FOMO, they feel decreased enjoyment of the current, chosen event and an increased expected enjoyment of the missed event (Rifkin et al., 2015). As FOMO leads one to overestimate the enjoyment of the missed event, consumers should feel further motivated to choose the option that will result in the least amount of FOMO without compromising their wellbeing.

\section{$2.4 \quad$ FOMO and technology}

Early research on FOMO suggests that this feeling has existed prior to technology through any communication channel that gave individuals insights on their family, friends, acquaintances, and strangers' lives. These forms of communication may be anything from an engagement post in the newspaper to letters, postcards, pictures, holiday cards or emails (Abel et al., 2016; Wortham, 2011). In our current technologically ridden-environment, individuals have the potential to know what hundreds of others, 
from strangers to close friends and 'frenemies,' are doing at a moment's notice sometimes even with various visual images.

Technological advances and wireless connectivity have enhanced the access to information and made 'being in the know' of what others are doing highly addicting (Abel et al., 2016). Although apps like Facebook and Instagram can cause FOMO, other communication apps like WhatsApp can result in a fear of missing out on the conversation. Individuals have WhatsApp groups with their closest friends, family members, students from a group project, or colleagues on their work team. Most FOMOrelated research has shed a great deal of light on social media's ties to FOMO, yet it is important to point out that this construct also pertains to keeping up with group chat messages (when possible), calls, and possibly even emails.

While plenty of researchers agree that FOMO is not a new concept nor is it experienced solely through social media, there is a consensus in the literature and industry that the rise of technology, and consequently social media, has significantly increased FOMO's frequency and intensity (Abel et al., 2016). According to Vaughn (2012), a 'key driver' of FOMO today is the blast of real-time updates on social networks. For instance, stories, a form of social media post which is only visible for 24 hours before it disappears, tend to heighten the reason for the FOMO (Vaughn, 2012). Social media is one of the main forms of communication amongst young adults, with $71 \%$ of individuals engaging on social media through their mobile devices (Hertz et al., 2015).

Social media platforms can benefit individuals by providing them with a direct channel for communication, knowledge, entertainment, and a means for self-expression (Kim, Jeong, \& Lee, 2010). Particularly, communication via direct messages, comments, and posts has been argued to be one of the most popular means of electronic communication (Abel et al., 2016). Ninety percent of adult millennials admit that they 
enjoy finding out what their social groups are up to through social media (Vaughn, 2012). Interestingly, $43 \%$ of adult millennials also believe that social media has amplified their FOMO (Vaughn, 2012). Research on social media engagement posits that individuals avoiding negative states like loneliness (Burke, Marlow, \& Lento, 2010), boredom (Lampe, Ellison, \& Steinfield, 2007), and dissatisfaction with one's current relationships (Ellison, Steinfield, \& Lampe, 2007) are more prone to using social media.

It is suggested that people use social media as an attempt to avoid negative mood states and feelings of being "out of the loop" (Fox \& Moreland, 2015). The relationship between social media and FOMO can be cyclical in nature (Przybylski et al., 2013). Individuals tend to feel pressured to continue to use Facebook due to FOMO and, in turn, experience more FOMO from scrolling through social media feeds (Fox \& Moreland, 2015). While FOMO has been established as an outcome of social media usage, it has also been presented as an antecedent to social media engagement.

FOMO directly associated with social media platforms is also a source for stress (Vaughn, 2012). A survey of millennial consumers from the US, China, and Singapore reported that keeping up with their commitments on social media was stressful and time consuming (Vaughn, 2012). Furthermore, communication mediated by technology can also undermine self-reflection and decrease one's wellbeing (Tucker, 2011). In this stream of research, it is argued that constant communication through technology takes us away from important social experiences in the current moment, the 'here and now.' Whether it is on social media or communication apps, FOMO leads to high Internet use (Dossey, 2014) and problematic smartphone usage through a constant need to touch (Elhai, Levine, Dvorak, and Hall, 2016). On average, we tend to touch (i.e., tap, swipe, click, and type) our smartphones 2,615 times per day with the heavy users averaging daily touches of 5,427 (Winnick, 2016). 
Parker (Vaughn, 2012) believes that we are still very infantile in our relationship with technology and FOMO is part of this human-technology relationship. People are still at a learning curve when it comes to coping with FOMO and some are concluding that "enough is enough" and are deactivating their social media accounts or turning to apps like Forrest that block mobile devices for a period of time. Parker claims that people are beginning to be more aware of the negative effects that FOMO has on their lives and are devising ways of coping with it (Vaughn, 2012).

\subsection{Why is FOMO important}

The next section discusses the important implications of exploring this topic. Although there is little information on FOMO and already this construct seems to be an important factor in consumer decision making of the $21^{\text {st }}$ century, other reasons to explore FOMO have to do with the significant attention it has received from industry and the implications (i.e., positive and negative) that it has for consumers and their wellbeing.

\subsubsection{Anticipated FOMO and consumer decisions}

The most commonly accepted definition of FOMO across disciplines is the Przybylski et al., (2013) referring to the feeling consumers experience when "others are having rewarding experiences from which one is absent" (p. 1841). This definition; however, does not specify which social groups can lead to more FOMO or what kind of experiences are more capable of instilling more FOMO. As FOMO is something most consumers experience at one point or another and make consumer decisions based on this emotion, it is important to further explore this topic to identify the specific factors of this phenomenon.

\subsubsection{FOMO advertising appeals}

Today, FOMO is being exploited in advertising campaigns in various industries, yet we know little about how FOMO affects consumer behavior. Unlike the academic 
literature, industry has paid a great deal of attention to the FOMO phenomenon. According to Hodkinson (2016), commercial industries have capitalized on this concept by using FOMO-based advertising appeals particularly aimed at the young adult market. According to Hodkinson (2016) companies are making significant sales revenue in both products and services through the FOMO phenomenon.

The acronym FOMO gained popularity, in part, because it is clever in nature.

Advertisements that use FOMO appeals (FOMO) to call attention can be considered to be clever as well and are particularly intended for millennials whom as a demographic appreciate wit. I believe that FOMO can motivate consumers to use their resources of time and money in order to attend events or engage in experiences. Given the significant effort and resources companies put in creating FOMO ad appeals, it is indicative that they also believe that FOMO can be a strong motivator that affects consumer behavior. FOMO ad appeals will typically have a call to action along the lines of, "Don't miss out," and have been widely used by companies like Dunkin' Donuts, Lyft, and Eventbrite, among others (see figures 1 and 2).

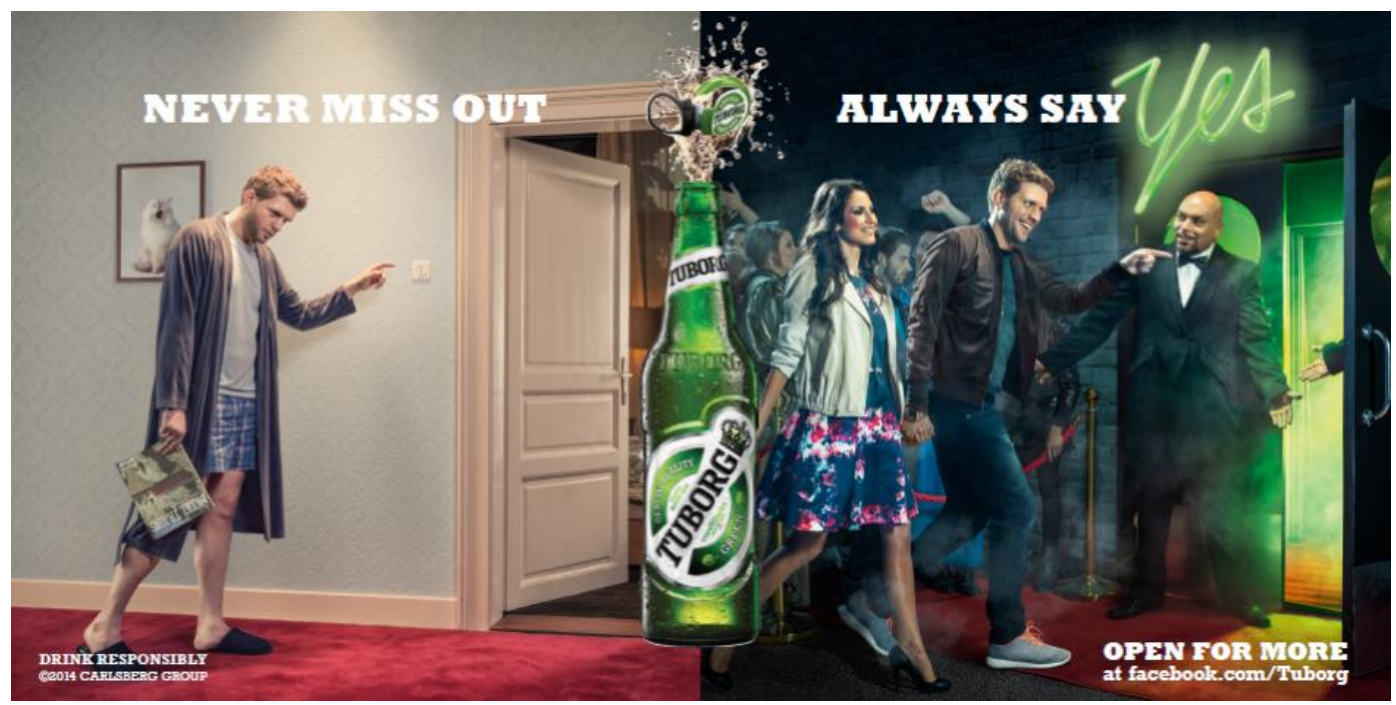

Figure 1. Tuborg' 2014 global campaign focused on "appeasing FOMO." 


\section{FOREVER 21 WOMEN ACCESSORIES PLUS + CURVE MEN GIRIS SAIE Search Products}

Forever Connected

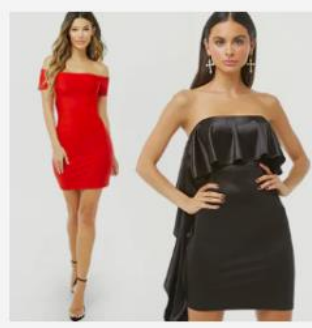

Shop Dresses

You've got things to do and people to see. The last thing you need is to wory about what to wear! Get dressed
without the stress and explore all our faves now!
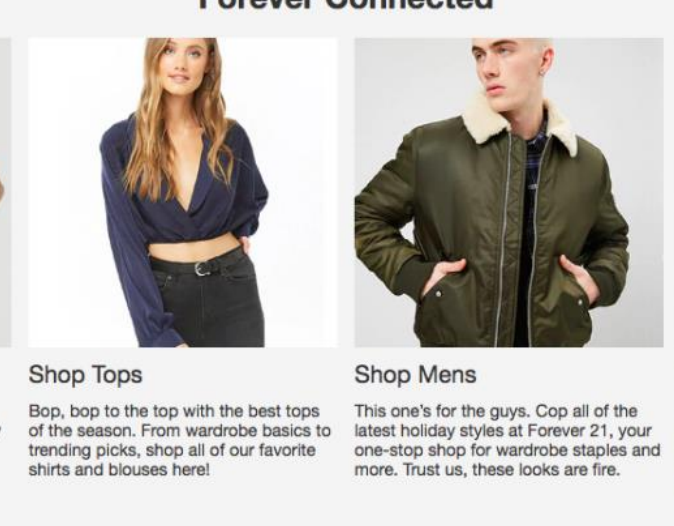

Shop Mens

This one's for the guys. Cop all of the latest holiday styles at Forever 21, your one-stop shop for wardrobe staples an
more. Trust us, these looks are fire.

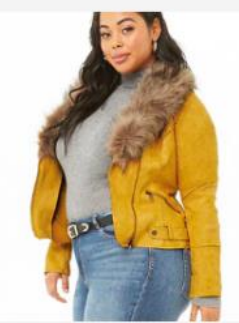

Shop Plus \& Curve

Get ready for all of your upcoming

holiday events with show-stopping

dresses, jumpsuits, and more! Everything you need for the most

Fear of missing out?

Be the first to know about the latest deals, style updates \& morel

EMAIL ADDRESS

Figure 2. Fashion store, FOREVER21, uses FOMO's defining dimensions of "being in the know" and staying connected on their website (accessed January 2019) as a call to action to enroll in email campaigns.

\subsubsection{Negative implications of FOMO}

FOMO has been explored in various contexts, particularly pertaining to how it negatively impacts students. FOMO has been commonly connected to reducing wellbeing because it may motivate individuals to partake in social activities that they may not necessarily have a desire to join in (Przybylski et al., 2013; Ryan \& Deci 2000). Even when an individual feels certain that he/she made the right choice in social activity, they may experience FOMO for all the missed events. FOMO has been seen to increase expected enjoyment of the missed events and decrease actual enjoyment of the chosen event (Rifkin, Chan, \& Kahn, 2015).

FOMO can lead to constant mobile checking behavior (Collins \& Van Abeele, 2013; Hato 2013), which in turn adds to the decreased enjoyment of the present activity. If one is constantly immersed in finding out what other possibility for enjoyment is out there, it is inevitable that one will not appreciate and enjoy the current experience and be 
'here and now'. Furthermore, the literature has largely associated FOMO with a plethora of negative outcomes ranging from reduced mindfulness (Baker et al., 2016) to increased alcohol use (Riordan, Flett, Hunter, Scarf, and Conner, 2018).

One of the most severe outcomes of FOMO is distracted driving (Przybylski et al, 2013). According to the DMV.org, 26\% of car accidents in 2014 involved cell phone usage, which is one of the most dangerous forms of distracted driving. Every day, at least 9 people die because of a distracted driver and $42 \%$ of teens report that they have texted while driving. Texting and driving is the leading cause of death in teens (DMV, 2015). People know that texting and driving is dangerous, yet they still do it (Projectyellowlight.com). This mobile behavior has led to the rise of organizations such as Project Yellow Light which are aimed at bringing awareness to this social problem that has arisen with the change in technological climate, social media and their byproduct: FOMO. The rise of organizations that promote mindful attention while driving is one way that individuals and society are coping with the effects of FOMO and acclimating to the learning curve brought upon by the rapid advances in technology.

Furthermore, in efforts to enhance their social media profiles, some individuals have suffered detrimental consequences to take a picture for the ultimate post. For instance, social media star Gigi Wu known for climbing to summits and taking pictures in bikinis (i.e., the 'bikini climber') fell down a ravine to her death in a national park in Taiwan while trying to take a photo. Media reports indicate that this is but "the latest in a string of social media adventure seekers who have met an untimely end" (South China Morning Post, 2019).

\subsubsection{Positive implications}

FOMO is by nature a motivational construct and as such, can motivate consumers to behave in ways that can lead to positive outcomes (University of Southern 
Queensland, 2017). When it comes to anticipating future FOMO, the fear of missing out may propel individuals to take action and join in a social activity due to either an intrinsic motivation to connect with others or an extrinsic motivation to avoid social punishment. In this manner, FOMO can have a positive influence on individuals by encouraging them to leave their comfort zone, meet new people, and experience new things.

Although FOMO can lead to comparing behavior in which individuals measure their current situations against that of others (Abel, 2016), this may not necessarily be a negative thing if it encourages individuals to engage in a new experience. For instance, if Fred from human resources, who has a similar lifestyle to myself, can go backpacking through South East Asia with a couple of friends, why can't I? Social media is designed such that the consumers are the content creators. Facebook, with a current market capital of $\$ 389.92$ billion (Google Finance accessed January 2, 2019), creates zero content, it curates what consumers see through algorithms. This means that a great deal of the experiences being diffused on Facebook are predominantly consumer generated content with the remaining being advertising.

Research posits that social media is pivotal in the tourism industry (Holm, Lugosi, Croes, \& Torres, 2017). The tourism industry has focused significant efforts on researching how FOMO affects consumer consumption. The findings indicate that "FOMO is one of the biggest reasons millennials travel" (Marketing M, 2016; p. 6), and $68 \%$ of millennials said that, they have made impulse purchase decisions within hours after seeing another person's travel experiences because of FOMO. Consumers view and post about their travels and by doing so create a form of travel diary online (Holm et al., 2017: Vu, Li, Law \& Zhang, 2017). Individuals who see their friends and acquaintances on social media travelling constantly experience FOMO and travel more because of it (Torres, 2016). According to the tourism literature, "travel increases a 
heightened sense of awareness of the brevity of the present" (Torres, 2016; 2148), which in turn can lead to FOMO. Torres (2016) found that FOMO, the influence of other travelers, and a desire to forge a new identity resulted in individuals being more open to travel experiences including risky ones; moreover, these risk-taking travel experiences are drivers for positive outcomes such as self-actualization. 
CHAPTER III. LITERATURE REVIEW ON FOMO 


\subsection{Theory of motivation and FOMO}

The literature on FOMO has studied the fear of missing out as a motivational construct that can affect human behavior (Przybylski et al., 2013). It has been linked to self-determination theory and the three basic psychological needs of competence, autonomy, and relatedness to others (Nadkarni \& Hofmann, 2012; Przybylski et al., 2013; Ryan \& Deci, 2000; Seidman, 2013). Individuals who report low satisfaction of these basic needs tend to experience higher levels of FOMO (Przybylski et al., 2013). FOMO could serve as a mediator between these three basic psychological needs and social engagement, which suggests that FOMO may be an antecedent for social interactions (Przybylski et al., 2013). Furthermore, people can be motivated by FOMO to engage in behaviors, such as going to a party instead of staying at home to catch up on much needed rest, in an attempt to avoid the negative feelings that might emerge should something fun happen for which one is simply not a part.

One stream of research finds that FOMO is associated with the need for approval and the need to belong (Lai, Altavilla, Ronconi, \& Aceto 2016). According to Rifkin et al., 2016, FOMO is driven by social belonging uncertainty, which individuals experience when they are concerned that their group membership is at risk. In a study where participants saw photos of a missed event (i.e., party), participants who imagined themselves at a concert experienced decreased expected enjoyment of the current event as well as an increased expected enjoyment of the missed event, even though the missed event was originally thought to be less enjoyable than the concert. In this case, higher social belonging uncertainty was associated with decreased enjoyment of the current event when the scenario included party photos. Participants who did not see photos did not experience as much FOMO (Rifkin et al., 2016). 


\subsection{Antecedents of FOMO}

Identified antecedents of FOMO include low levels of satisfaction of the basic human needs of competence, autonomy, and relatedness. In other words, people whose needs for competence, autonomy and relatedness are not being met tend to feel higher levels of FOMO (Przybylski et al., 2013). A negative mood can also lead people to experience FOMO. It is possible that depressed individuals may be more susceptible to FOMO, because they may feel as if they are hopelessly competing for care, acceptance, and social support from others (Baker et al., 2016). Higher levels of FOMO have been seen in younger people and particularly in males (Przybylski et al., 2013). Finally, another known antecedent of FOMO is overall low life satisfaction. Individuals who are generally dissatisfied with their current situation are more prone to experiencing FOMO.

While FOMO has been established as an outcome of social media usage, it has also been presented as an antecedent to social media engagement (Przybylski et al., 2013). This engagement may include seeing posts as well as posting behavior which results in others experiencing FOMO from that particular posting behavior (Fox \& Moreland 2015). In a study of adventure travel, Hay (2013) proposes that people try to maximize their vacation to ensure that they have selected the option with the most "cutting edge tourism experiences." This can increase feelings of anxiety for the consumer, which leads him/her to prove that his/her chosen experience is the best through constant updates and posts on social media. Consistent with these findings, students in travel abroad programs reported having purposely promoted feelings of FOMO to their social connections back home through social media posts, and waiting for the optimal times to receive the most likes and comments (Hertz et al, 2015).

The FOMO literature also includes scarcity advertising appeals (Hodkinson, 2016). While both explicit FOMO ad appeals and scarcity ad appeals may trigger 
feelings of FOMO, they differ in that scarcity appeals focus on the product, its limited nature and perceptions of limited time offers; whereas FOMO appeals focus on the consumer and attempt to amplify their internal uncertainty in order to motivate them to take some action.

The literature, however, has not explored the antecedents as much as it has the outcomes. I intend to explore other antecedents of FOMO tied to the situational elements resulting in high FOMO for the general population. I also propose marketing related outcomes and provide an overview of the explored consequences to FOMO. Our research thus advances the literature by investigating the previously unexplored antecedents of social groups and type of experience.

\subsection{Consequences of $\mathrm{FOMO}$}

The consequences of FOMO have been explored in various disciplines such as social psychology and education. Naturally, many of the known outcomes are closely related to students and wellbeing and have little to do with consumer behavior. Some of the most noted consequences include the use of social media, such as increased engagement and posting behavior (Fox \& Moreland 2015; Przybylski et al. 2013), less mindful attention (Baker et al., 2016), and decreased life satisfaction and wellbeing (AlMenayes, 2016; Przybylski et al., 2013). FOMO has also been seen as a source of negative mood or depressed feelings (Baker et al., 2016) because it undermines the sense that one has made the best decision possible on a given occasion (Wortham, 2011). Consequently, FOMO leads to a two-pronged effect: decreased enjoyment of the attended event and increased expected enjoyment of the missed event (Rifkin, et al., 2015).

FOMO has been considered to be the driving force behind high Internet use (Dossey, 2014) leading to constant checking of mobile phones (Collins \& Van Abeele, 
2013; Hato, 2013). FOMO tends to be high in students who access their social media accounts in class (Przybylski et al., 2013). In a study where students' mobile devices were temporarily taken from them, participants experienced high levels of anxiety, FOMO was believed to be the underlying reason (Cheever, Rosen, Carrier, \& Chavez, 2014). FOMO may also lead to alcohol use (Riordan et al., 2015).

FOMO can drive consumer spending in that it tends to motivate consumers to do more (Abel et al., 2016; Vaughn, 2012). FOMO affects the travel industry as well. Currently companies are using a great deal of FOMO appeals in its adverting campaigns. Another consequence explored in hospitality and tourism journals includes rural tourism visitation behavior or adventure travelling (Hay, 2013). Consumers who view stimuli of travel on social media are more likely to travel as well because of FOMO (Torres, 2016). In contrast, Rifkin et al. (2016) found that promoting FOMO through social media posts does not mitigate one's own feelings of FOMO and suggest that FOMO is not driven by the motivation to "keep up" with others. In contrast, other researchers believe this phenomenon is about being in the know and propose that FOMO may be the reason for watching one-time programs like the Super Bowl (Conlin, Billings, \& Averset 2016).

Some of the more serious consequences of FOMO that have been studied include negative health outcomes and physical symptoms (Baker et al., 2016), anxiety (Elhai, Levine, Dvorak, \& Hall, 2016), and loneliness (Dossey, 2014). FOMO has also been seen to result in distracted driving (Przybylski et al., 2013). FOMO, a social constuct in nature, can paradoxically lead to feeling increasingly lonely when individuals substitute in-person interactions for social media contact (Dossey, 2014). 
CHAPTER IV. FOMO AS A SOCIAL CONSTRUCT 


\subsection{Introduction}

The desire for social relationships is one of the most fundamental and universal human needs (Mead, Baumeister, Stillman, Rawn, \& Vohs, 2011). It has been shown that a lack of attachments leads to various negative effects on health and wellbeing (Baumeister \& Leary, 1995; Bowlby 1973; Bowlby 2008); therefore, individuals tend to place high importance on creating and maintaining interpersonal connections.

Feelings of belongingness have various effects on emotional patterns and cognitive processes (Baumeister \& Leary, 1995; Weiss, 1973). Emotion theorists agree that emotions vary in different contexts and serve distinct functions (Lazarus, 1991) with the intensity of emotions varying depending on relationship closeness. For instance, at the high end of the spectrum on emotion intensity is love. The love that one shares with friends and family functions to foster relationships, influences bonding (Gonzaga et al., 2006), and creates feelings of warmth and closeness (Fitness \& Fletcher, 1993) in human relationships. These feelings of love and closeness are not generally felt for weaker or less close social ties (i.e., acquaintances).

\subsection{Tie Strength Theory}

Tie strength is a construct that has been vastly explored in the literature, where one's close friends and family are considered to be strong ties and acquaintances and more distant social groups are considered to be weak ties. Granovetter (1973) opened the conversation on the impact of social bonds on different social circles when he published his theory on the strength of weak ties (SWT). This theory suggests that there is a great deal of importance in a somewhat neglected social group in the literature: the acquaintances, distant others, or more specifically, what Granovetter coined the "weak ties." According to SWT theory, weak ties are of high importance because they provide greater social reach or consequence in the flow of information. For instance, an 
individual called Fred has a close group of friends (strong ties) whom are all close with one another (i.e., a social group). Fred will also have several acquaintances (weak ties) from work, school, gym, etc., and each of those weak ties will, in turn, have their own close social groups (strong ties). These various groups would be otherwise entirely unconnected if it wasn't for the existence of weak ties (Granovetter, 1973, 1983).

Tie strength has been used in many contexts to explain how small-scale interaction affects macro phenomena such as diffusion of information and ideas, social mobility, political organization, and word of mouth (Brown \& Reingen, 1987; Wirtz \& Chew, 2002). Many researchers have used this theory of micro-level interactions to explain macro-level patterns (Granovetter, 1973); the small-scale contacts and social connections explained in the theory have furthered a great deal of research.

\subsubsection{Definition}

The seminal paper on tie strength by Granovetter (1973, p. 1361) explains that "the strength of a tie is a (probably linear) combination of the amount of time, the emotional intensity, the intimacy (mutual confiding), and the reciprocal services which characterize the tie." Many researchers identify the word "acquaintances" with weak ties and "friend" with strong ties (Ericksen \& Yancey, 1980; Granovetter, 1973; Lin, Ensel, \& Vaughn,1981). Participants who identified social ties as "acquaintances" or "friends of friends" were considered weak ties, while classifications like "friends," "relatives," or "neighbors" were deemed strong ties. In one paper, PhDs mentors and dissertation advisors were also identified as strong social ties (Murray, Rankin, \& Magill, 1981).

Strong ties are considered to be those whom one really trusts and can count on, individuals with whom one has friends in common (Gilbert \& Karahalios, 2009). The educated, the young, and the metropolitan may particularly have more diverse social ties (Marsden, 1988). In contrast, weak ties can help one gain new information, learn about 
fashion trends or identify job opportunities more than strong ties because of the information flow that goes from group to group linked through weak ties (Gilbert \& Karahalios, 2009).

Researchers have studied tie strength using various dimensions for classifying this construct such as by the frequency of contact (Granovetter, 1973; Lin et al., 1981) and reciprocity of the relationship (Granovetter, 1973), as well as the closeness (most widely used), duration, breath of topics discussed, and confiding behavior (Marsden \& Campbell, 1984). Yet studies aimed at measuring tie strength more accurately found that the best measure of tie strength is closeness (Marsden \& Campbell, 1984). As a measure, 'closeness is the best indicator most highly associated with tie strength' (Marsden \& Campbell, 1984).

\subsubsection{Strong ties}

"Tell me who your friends are, and I'll tell you who you are" - Old Spanish proverb.

There is sufficient evidence that suggests that the stronger the interpersonal tie between individuals, the more they tend to be similar in various ways (Bramel 1969; Brown 1965; Laumann 1968, Newcomb 1961; Granovetter, 1973). One of these ways can be explained by homophily, which refers to the extent that close individuals have similar attributes such as age, gender, social status, and education (Brown \& Reigen, 1987). While tie strength is defined by the intensity of a relation between consumers, homophily focusses on the communication or interactions between similar consumers (Brown \& Reingen, 1987). Because people tend to become closer to those with whom they share certain similarities, it is likely that individuals would prefer to engage in activities where people with whom they have the most in common with are involved. 


\subsubsection{Weak ties (the strength of weak ties)}

The literature posits that more people can be reached through weak ties. For instance, without the connection of weak ties, it would not be possible to generate the momentum necessary for the recruitment of clubs or organizations and would not spread outside of strong social tie groups. "Weak ties, far from creating alienation, are actually vital for an individual's integration into modern society." (Granovetter, 1983, p. 203). While individuals are more motivated to invest time and resources to help their strong ties (i.e., close friends and family), sometimes weak ties (i.e., acquaintances) have a wider reach of influence because of the different links and opportunities various weak ties have access to, forming a longer the chain of influence (Granovetter, 1983).

\subsubsection{FOMO and tie strength}

Past FOMO research recognizes that other people can play a role in elevating FOMO (Al-Menayes, 2016; Przybylski et al., 2013), but it has not distinguished which types of social ties cause consumers to experience more FOMO. In the current manuscript, I build on past literature by identifying which social ties, strong or weak, are more likely to result in higher levels of FOMO in consumers. To do so, I conceptualize close social ties as family and closest friends, while a distant social tie may be acquaintances from work, school or other activities, whom one does not know very well. Because the level of closeness and affection varies between social ties, I believe that FOMO levels should also vary for experiences involving individuals of varying tie strengths.

In a qualitative study where 198 participants were asked what FOMO meant to them, $75 \%$ of participants made references to their social group or friends (Rifkin et al., 2016). Past research has indicated that people are motivated to share experiences with individuals to which they are close. For instance, in romantic relationships, the quality of 
the relationship is enhanced when the partners share novel and challenging activities (Aron, Norman, Aron, \& Lewandowski, 2002; Aron, Norman, Aron, McKenna, \& Heyman, 2000; Boothby, Smith, Clark, \& Bargh, 2017). Furthermore, I believe consumers will be more willing to invest their resources of time and money on strong social ties than on weak social ties.

\subsection{Social exclusion}

Throughout history, the human race has opted for living in settlements, towns, and cities rather than living in total isolation. At a biological level, this tendency improves survival outcomes of the species (Twenge, Baumeister, DeWall, Ciarocco, \& Bartels, 2007). So, "being accepted into a social group is an almost indispensable goal of human striving" (Baumeister, DeWall, Ciarocco, \& Twenge, 2005, p. 589). However, in order for individuals to be included by society, they must be able to behave in ways that conform to the social norms around them; in other words, they must be able to employ selfregulation (Baumeister et al., 2005).

Although social exclusion can be common and most individuals have experienced social exclusion at some point or another, scientific studies using fMRI suggest that the social pain experienced from social exclusion reflects similar patterns in the brain to that of physical pain (Eisenberger, Lieberman, \& Williams, 2003). According to Freedman, Williams, and Beer (2016), socially excluded individuals want to restore their self-esteem, to have a meaningful existence, to belong, and to have control over themselves. For these reasons, social exclusion has been seen to lead to conspicuous consumption and donating behavior (Lee \& Shrum, 2012), but it also leads to poor selfregulation (Baumeister et al., 2005), more aggressive behavior (Buckley, Winkel, \& Leary, 2004; Twenge, Baumeister, Tice, \& Stucke, 2001), and self-destructive tendencies (Twenge, Catanese, \& Baumeister, 2002). These outcomes are dissimilar to 
those of FOMO in that individuals tend to emotionally react much more intensely and destructively than after experiencing FOMO, which has a lighter nature.

The construct of FOMO differs from social exclusion mainly in that one does not need to be ostracized from a group or activity to experience FOMO. On the contrary, FOMO can be experienced even for events from which one voluntarily chooses to exclude oneself for various reasons, given that time is limited, and one cannot be present for everything. It is important to make this distinction because there are detrimental effects to one's self-esteem and social pain that socially excluded individuals may feel that individuals experiencing FOMO may not. I am looking at FOMO from a social inclusive perspective (i.e., should participants not attend an event by their own choice). 
CHAPTER V. FOMO AND ANTICIPATED REGRET 


\subsection{FOMO vs. Anticipated Regret}

While FOMO is an emerging construct in the consumer behavior literature, it may be natural to associate FOMO with anticipated regret, a better-developed construct. Regret is a negative emotion a person may experience upon realizing that their present situation would have been better had they decided differently (Zeelenberg \& Pieters, 2007). When one is faced with making decisions, we may anticipate regret for the potential outcome of our choices and thus affect the decision-making process (Zeelenberg, 1999). I believe that FOMO and anticipated regret are two different constructs that are correlated. As part of this dissertation, I intend to highlight the main principles upon which these two constructs differ and how they relate. I posit that anticipated regret and FOMO differ in that (1) FOMO has a social element not tied to anticipated regret, (2) FOMO, unlike anticipated regret, can be felt for circumstances that involve no choice, and (3) anticipated regret, unlike FOMO, is ruled by a factor of responsibility.

\subsection{Social nature}

The main difference between FOMO and regret lies in the premise that FOMO is a construct that has a strong social element that is lacking in the construct of anticipated regret. For experiential consumption, it is hard to separate FOMO from its social nature. Individuals feel FOMO when friends are engaged in experiences that one is missing out on. More specifically, missing out on the chance to engage in social interaction or to miss shared memories and inside jokes, which can motivate consumers to engage in a given experience. Furthermore, I believe that it is difficult to experience FOMO with activities that do not involve spending time with others or have a social-related outcome, while anticipated regret does not need to have a social element (i.e., I can come to regret later not buying that Garmin watch on sale). I posit that with anticipated regret, 
the focus is strongly related to the activity itself, for instance possibly regretting not seeing Cirque du Soleil when they are in town, whereas with FOMO the focus is on the social element such as not missing out on having a good time at the circus with friends. So anticipated regret and anticipating future FOMO can motivate consumers in similar ways but regret focuses more on the potential missed experience (and the choice aspect) while FOMO has a stronger focus on the missed chance for social interaction (and the particular group).

\subsection{Choice element}

When comparing FOMO and regret past the decision-making stage, feeling regret in general requires the existence of another, unchosen option (Zeelenberg, Van Dijk, Manstead, \& Pligt, 1998) and logically, people try to avoid experiencing regret whenever possible (Bell, 1982). In contrast, FOMO does not necessarily require the existence of another option in order to be experienced. In other words, people may feel FOMO for a present or future event even if they did not have the opportunity to actively make a choice about attending or not. Individuals may feel FOMO when they never had the option of joining in a social event, as well as when they were presented with the option but decided not to participate.

Moreover, when individuals do have the opportunity to make a choice, feeling FOMO for a foregone option does not necessarily indicate that the person regrets their decision. One may feel FOMO simply upon realizing that there is a social interaction that is taking place from which one is absent. People may experience FOMO even for events that are happening on the other side of the world and are highly geographically or financially unattainable (i.e., a family wedding in Europe when you know you cannot justify the time or money to attend), or for events one has to miss due to another 
obligation or opportunity. In these instances, individuals would generally not regret their decision, but they can and likely may experience FOMO.

For instances in which an individual does have the opportunity to make a choice of whether to attend an upcoming social event, FOMO and regret can be felt simultaneously. Just as one can anticipate experiencing regret in the future, one can also anticipate feeling FOMO in advance. While anticipated regret has been widely studied (Sandberg \& Conner 2008; Sheeran, \& Orbell, 1999; Zeelenberg, 1999; Zeelenberg \& Beattie, 1997; Zeelenberg \& Pieters, 2007), there is relatively little research on future FOMO. The limited findings that do exist indicate that individuals tend to feel higher FOMO for events that are happening in the present than for events taking place in the future or that have already taken place. Looking at this anticipatory FOMO is important because it can lead consumers to act on this emotion and part with their resources of time and money to mitigate their FOMO.

When it comes to anticipated regret, the existence of another option is required. For instance, Fred visiting a restaurant in New Orleans is not sure whether to order the jambalaya or the chargrilled oysters; he ultimately picks the jambalaya only to see the person at the next table receive a plate of sizzling chargrilled oysters and immediately wishes he had ordered the oysters. This man can regret not getting the oysters because it was ultimately his choice that he is regretting due to the perceived benefits the oyster plate seemed to have over the jambalaya. However, if the chargrilled oysters were not offered on the menu or advertised by the waiter and the person on the other table, perhaps a regular, still received the chargrilled oysters, the person that ordered the jambalaya may feel angry, upset, or even cheated, but he wouldn't be regretful because he never had the choice to order the oysters. He can certainly feel like he is missing out on tasting those fresh chargrilled oysters. 
The comparison between possible alternatives influences consumer behavior (Tsiros \& Mittal 2000), which is why anticipated regret can lead people to behave in ways aimed to reduce the potential for subsequent regret (Loomes, Starmer, \& Sugden, 1992; Ritov, 1996; Zeelenberg \& Beattie 1997; Zeelenberg, Van Dijk, Manstead, \& der Plight, 1998). Anticipated regret can also influence current decisions with uncertain outcomes, causing people to think more carefully before making a decision (Zeelenberg, 1999). People sometimes base their decisions on a minimax regret principle, which holds that one estimates the maximum possible regret for each option and then chooses the option where the regret is anticipated to be the smallest (Luce \& Raiffa, 1957). Because of the availability of many activities and various options for spending our time, I posit that people also tend to choose the option that will minimize FOMO for events that are plausible to attend, yet it is likely they may still experience a degree of FOMO from the forgone options without necessarily regretting their decision. That is, FOMO can be felt for upcoming future events that an individual may not be able to partake in, and chooses to miss out on, due to financial constraints or prior commitments or obligations. In this case, this individual does not regret their decision of not parting with their resources of time and money, yet does feel FOMO for not attending.

\subsection{Responsibility element}

Regret is also ruled by a factor of responsibility because decision makers generally feel they have more control over avoiding future misses, or opportunities they decide to miss out on in the future, than past misses, or opportunities that already passed (Zeelenberg, Van Dijk, Manstead, \& der Pligt, 2000). For instance, in a study where participants are given the option to purchase a product that had been on sale the previous week versus a product that will be on sale the following week, participants preferred the option associated with past promotions than future promotions because 
they experience more regret and responsibility for missing a future promotion (Shani, Danzigera, \& Zeelenberg, 2015).

When it comes to FOMO, one does not need to make a choice in order to experience this feeling, so in these cases there is little responsibility to be considered. However, quite often, we experience FOMO because we have too many options of things to do (i.e., responsibilities and leisure activities) and not enough time to be a part of everything. For instances where a decision is involved, one would initially experience FOMO and subsequently try to minimize their anticipated regret when making a decision. As I believe that anticipated regret is an outcome of FOMO, I posit that the factor of responsibility does not lie in the fear that others are having better experiences than one is (i.e., FOMO) but in the actual concern of making the wrong choice (i.e., regret). 
CHAPTER VI. FOMO AND EXPERIENTIAL CONSUMPTION 


\subsection{Consumption of experiences}

Although acquiring material possessions is quite alluring, consumers also aim to acquire experiences in order to enjoy greater happiness (Bhattacharjee \& Mogilner, 2013; Howell \& Hill, 2009; Van Boven \& Gilovich, 2003). Harris Poll and Eventbrite found that $78 \%$ of Generation Y participants would rather spend their money on an experience than a material good, compared to $59 \%$ of baby boomers. Their findings indicated that generation $\mathrm{Y}$ values experiences very highly and is willing to invest more time and money on experiential consumption (Vaughn, 2016). These results support the academic literature on materialism and experiential consumption reviewed next.

Van Boven and Gilovich (2003), define experiential purchases as "those made with the primary intention of acquiring a life experience: an event or series of events that one encounters, lives through, and 'consumes'" (Van Boven, 2005, p. 134). Experiential purchases provide greater satisfaction and happiness to consumers than material purchases as they tend to be less prone to comparisons and may form a part of a person's identity (Gilovich, Kumar, \& Jampol, 2015; Van Boven, 2005).

Airbnb's (2016) research on experiential consumption revealed that when millennials were asked which they believed to be amongst the most important (i.e., travelling, purchasing a home, purchasing a car, or paying off debt), over half $(58 \%)$ said travelling. There is also a positive stereotype associated with experiential purchasers (Van Boven, 2005). Choosing to spend discretionary income on experiences rather than material possessions may portray consumers more favorably. For instance, in a study in which participants were asked to read the profile of two different students and rate their impressions about them, the student that preferred to spend his income on skiing or snowboarding was rated more favorably than the one who preferred to spend his money on computers and digital watches (Van Boven \& Gilovich, 2004). Experiences can also 
give us pleasure in retrospect. Even when an experience has passed, one can relive it and derive pleasure from it simply by revisiting the experience in memories and through story telling (Mitchell, Thompson, Peterson, \& Cronk, 1997; Van Boven, 2005).

Furthermore, experiences tend to form a fundamental part of the self (Carter \& Gilovich 2012). They allow individuals to grow and learn in various ways. Because a person's experiences live on in their memories and narratives, they tend to become parts of their autobiographies (Carter \& Gilovich 2012) -- hence the saying: we are what we do.

\subsection{Social Experiences}

Experiences also provide great satisfaction and happiness because they have the ability to foster and nurture social relations (Gilovich et al., 2015). In a study conducted by Eventbrite (n.d.), 69\% of participants (millennials) report that attending events makes them feel more connected to others, the community and the world.

Experiences also provide an opportunity to cultivate social relations with others. We use our discretionary income to go on vacation to ski resorts and go to dinner with other people resulting in experiences having a social value, as opposed to material things that can be more solitary in nature (Van Boven, 2005). Although some experiences can certainly be done on one's own, shared experiences have been seen as more enjoyable than solitary experiences (Caprariello \& Reis, 2013). Furthermore, spending money on others versus oneself makes people happier (Dunn, Aknin, \& Norton, 2008). Hence, spending money to enjoy experiences with others makes one happier than a solo experience (Caprariello \& Reis, 2013). 


\subsection{Ordinary experiences}

Just as there is a clear distinction between material and experiential purchases, individuals experience events within categories which are systematically different and that are recognized as such by others (Bhattacharjee \& Mogilner, 2014). One of the ways experiences have been classified is based on how frequently the experience occurs. Under this system, ordinary experiences are those that are common and frequent, while extraordinary experiences are less common and do not occur with frequency (Bhattacharjee \& Mogilner, 2014).

There is a significant stream of literature that sheds light on the role of ordinary experiences in attaining happiness (Bhattacharjee \& Mogilner, 2014; Bryant 2003; Quoidbach, Berry, Hansenne, \& Mikolajczak. 2010). For example, it has been seen that savoring ordinary or mundane moments can increase happiness (Quoidbach et al., 2010) as long as this feeling is not undermined by the incapacity to be appreciative of these moments (Parducci, 1995). Furthermore, filling one's life with various ordinary experiences can increase total enjoyment (Bhattacharjee \& Mogilner, 2014; Nelson, Meyvis, \& Galak, 2009). Together, this research suggests that ordinary experiences can bring pleasure and enjoyment to life and can be appreciated by consumers as such.

\subsection{Extraordinary experiences}

Extraordinary experiences, which are less common, are deemed 'extraordinary' due to the level of importance for one's overall wellbeing or by how rare the experience is (Keinan \& Keivetz, 2008; Tversky \& Griffin, 1991), for instance the birth of a child or the trip of a lifetime. An extraordinary experience is significant for a person because it may lead to personal development and growth, by reaching life milestones, traveling and exploring new cultures, or fostering romantic connections and social relationships with others (Bhattacharjee \& Mogilner, 2014; Schmitt, Josko Brakus, \& Zarantonello, 2015). 
Even the memories of extraordinary and meaningful events have important consequences for one's self-definition, overall wellbeing and life satisfaction (Bhattacharjee \& Mogilner, 2013).

Consumers tend to be motivated to collect experiences to add to their "experiential resume" (Bhattacharjee \& Mogilner, 2013) and tend to derive utility from doing so (Keinen \& Kivets, 2008). This way, consumers can gain a sense of accomplishment and productivity by "consuming collectible (unusual, extreme) experiences" (Keinen \& Kivets, 2008, p. 937). It is suggested that rare opportunities are considered to be more collectible, and thus might lead to more FOMO, due to their novel and unique characteristics (Keinen \& Kivets, 2008). Social media is a common outlet through which to display one's experiential $\mathrm{CV}$, which may further motivate consumers to collect these kind of experiences (Hertz, Dawson, \& Cullen, 2015).

\subsection{Connection between FOMO and PI}

When making experiential purchase decisions, consumers tend to seek to avoid the feeling of FOMO. Consumers are often faced with making decisions about which social outing to attend (when two or more events will take place at the same time), or to miss out on outings because of other responsibilities or for personal care (i.e., need to rest). As one cannot be in two places at once and time is a limited resource, consumers are forced to make regular decisions on what to attend and which events to skip.

Accordingly, past research on experiential consumption indicates that consumers take pleasure in purchasing experiences that they can share together (Caprariello \& Reiss, 2013). Moreover, consumers tend to enjoy spending their money on others more than oneself because it results in greater happiness (Dunn, Aknin, \& Norton, 2008). If consumers like to use their discretionary income to invest it on others, I believe that they 
will be more likely to attend an event when they know that their friends or close relations will be attending. 
CHAPTER VII. AUTOMATICITY 


\subsection{Introduction}

Another scope of this research is to determine whether FOMO is an automatic or controlled process. Bargh (1989, p. 3) defined an automatic process as one that is "capable of occurring without the need for any intention that it occur, without any awareness of the initiation or operation of the process, and without drawing upon general processing resources or inferring with other concurrent thought processes. Essentially, a thought process that occurs without intention, awareness, or effort (Bargh, 1989; LaBerge \& Samuels, 1974; Posner, Snyder, \& Solso, 1975; Shiffrin \& Schneider, 1977). A more recent account of automatic processes defines it as "unconscious practices that happen quickly, do not require attention, and cannot be avoided" (Dijksterhuis, 2007; p. 85). Attitudes and stereotypes, for instance, have been seen to be activated automatically in the presence of the stimuli (Bargh, 1989; Bargh, Chen, \& Burrows, 1996; Brewer, 1988; Devine, 1989; Perdue \& Gurtman, 1990; Pratto \& Bargh, 1991).

A controlled process, in contrast, is defined by Bargh (1989, p. 4) as "those that are under flexible, intentional control of the individual, that he or she is consciously aware of, and that are effortful and constrained by the amount of attentional resources available at the moment." In other words, controlled processes, are conscious, intentional, require some kind of effort, and can be controlled (Gailliot, 2007).

There are components to automatic processes which he termed the four horsemen of automaticity: (1) conscious versus unconscious, (2) efficient versus inefficient, (3) intentional versus unintentional, and (4) controllable versus uncontrollable (Bargh, 1984). These components of automaticity are discussed in further detail below. 


\subsection{Conscious versus nonconscious}

Automaticity refers to whether a psychological process is conscious or nonconscious. While a conscious process means you are aware, for a process to be nonconscious it means that you are not aware of it (Dijksterhuis, 2007). A great deal of consumer behavior occurs through nonconscious processes (Dijksterhuis, Smith, van Baaren, \& Wigboldus, 2005). There are some behaviors that require more conscious attention than others. For instance, driving to a familiar place is a nonconscious process, meaning that one can drive with little effort, although it is a very conscious process when one is learning to drive.

A process is nonconscious when a consumer is unaware of one or more of the following types of awareness: (1) awareness of the situational features that cause the automatic process, (2) awareness of the automatic process itself, and (3) awareness of the consequences of that process (Chartrand, 2005). In other words, if the process happens without conscious awareness of what caused it, what is happening, or what it leads to, then the process is nonconscious.

\subsection{Efficient versus inefficient}

Generally, individuals can only do one thing at a time that requires conscious attention and effort. For instance, one cannot read a book and watch a TV show at the same time and fully keep up with either because they both require attentional resources; however, one can engage in an efficient process such as driving as it is done

effortlessly, and simultaneously engage in a conscious process like having a conversation with someone (Dijksterhuis, 2007).

In a way, when a process is efficient it is trusted because they happen so effortlessly. Individuals can trust the ease in which they make judgments and 
categorizations almost as much as they can trust what their sense are telling them (Bargh, 1994).

\subsection{Intentional versus unintentional}

Intentional processes happen when an individual wants them to happen, while an unintentional process happens regardless of an individual's desire of it to happen. Some of the behaviors we engage in are intentional, such as reading a book, going for a walk, etc. Yet, other things we may do are less intentional, such as our body language when we talk or the way we might mimic the other person's hand gestures during a conversation (Dijksterhuis, 2007).

In my past research with FOMO, I have noticed this feeling to be intentional and undesirable. Individuals are motivated to go out of their way to avoid feeling this way and don't like to admit to experiencing when they do. Yet, as we are social beings by nature, it is normal to want to be part of social interactions with our friends and family and experience FOMO from time to time.

\subsection{Controllable versus uncontrollable}

Controlled processes refer to the ability to stop a psychological process once it starts. In other words, we can stop when we want it to stop like talking or eating. Uncontrolled processes cannot be stopped, for instance closing your eyes when you are about to sneeze. Driving is a controlled process because you can stop whenever you want (Dijksterhuis, 2007).

Psychological processes are not either fully automatic or fully controlled but tend to have a bit of both, with the exception of reflexes which are fully automatic (Bargh, 1984, 1989; Dijksterhuis, 2007). When it comes to FOMO, I believe that it starts as an automatic process that with time can be diminished, although not fully controlled unless one has no interest in being part of a certain event. In a focus group session part of this 
dissertation, when I explored experiential consumption motivated by FOMO, participants were at first reluctant or unwilling to admit to experiencing FOMO. In fact, in most FOMO accounts shared throughout the discussion, participants exclaimed that they hardly experience it anymore. However, when I gave participants scenarios with FOMO in a non-explicit manner, participants did report feeling FOMO via a scale.

While FOMO can come as an emotion that can motivate consumers to make purchases, I believe that when one starts to feel FOMO after receiving a stimuli such as glancing through social media or hearing of an event one may not be able to attend; however, when one has the time to rationalize the circumstances, then one is able to control these emotions more in ways that diminish FOMO. I posit that FOMO falls on the automatic side of the spectrum. 
CHAPTER VIII. RESEARCH PLAN \& HYPOTHESES 


\subsection{Theoretical Framework}

My theoretical model provides antecedents for experiencing FOMO that are circumstantial in nature and are not based on consumer's individual differences. It begins to answer the question, under what circumstances does FOMO tend to affect consumers in general? I propose that a main antecedent of FOMO is the type of tie strength that consumers have with the people involved in an activity. The stronger the tie (i.e., close friends), the more FOMO an individual may feel for the potentially missed experience. Conversely, I anticipate that individuals will feel less FOMO when people with whom the individual has a weak-tie (i.e., acquaintances) are involved in the activity. I also propose that the type of experience will affect the level of FOMO depending on social tie strength. I posit that when an experience is extraordinary, consumers will report higher levels of FOMO for the missed event if strong ties are involved in the activity and that there will not be a significant difference between social ties when an experience is ordinary.

In addition, I explore the relationship between FOMO and anticipated regret. I believe that FOMO is the fear of future regret; therefore, I propose FOMO as an antecedent to anticipated regret and that together, they can lead to purchase intent. The conceptual model of the serial mediated moderation can be seen below (see figure 3). This is the first empirical research, to my knowledge, to consider purchase intent as a consequence of FOMO. 


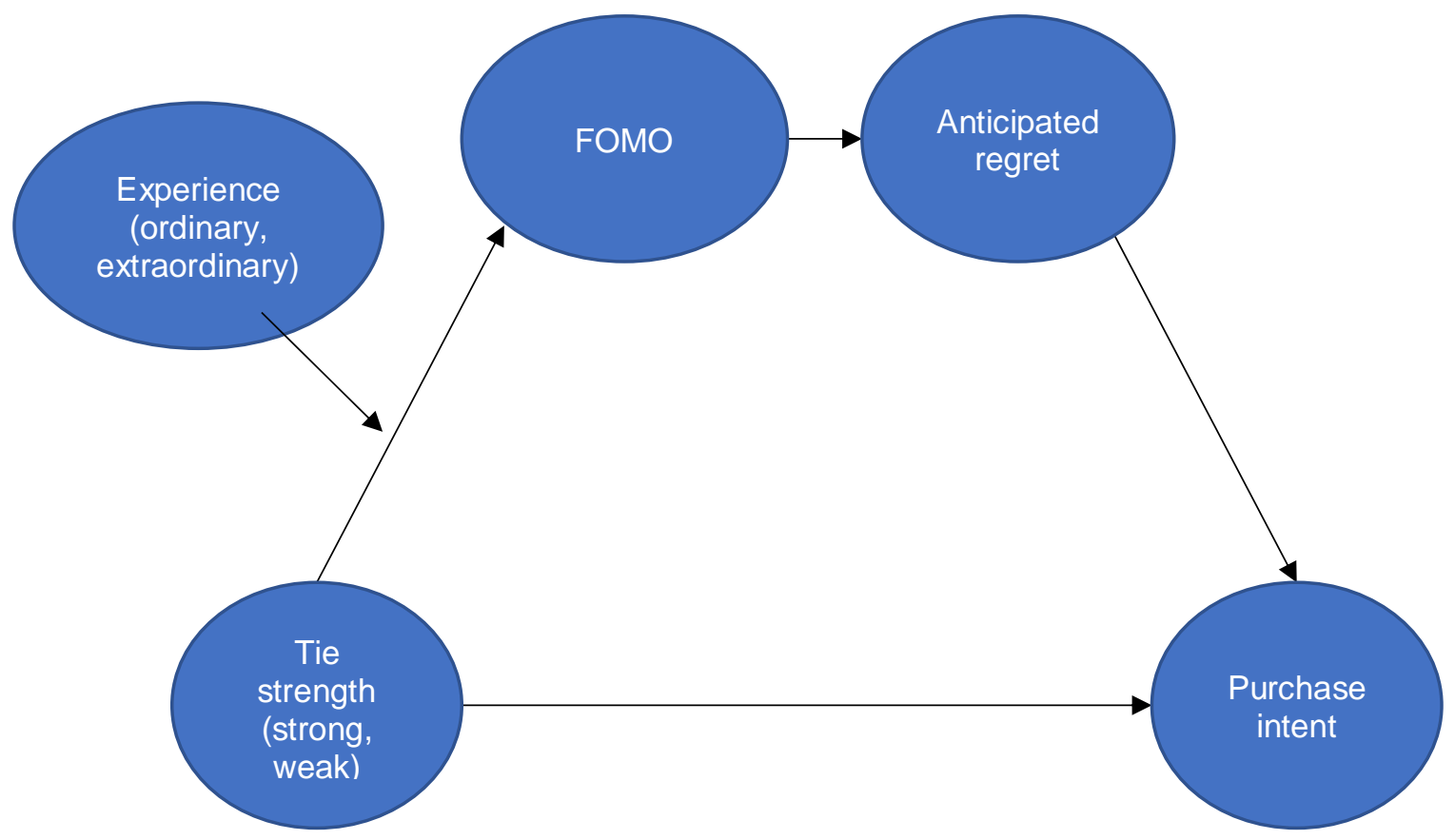

Figure 3. Conceptual model (serial moderated mediation)

\subsection{Hypotheses}

I believe that there are some situations that are likely to cause most individuals to experience FOMO. As relationships with strong social ties involve a stronger bond than do relationships with weak social ties, and individuals are motivated to share experiences with loved ones (Aron, Norman, Aron, \& Lewandowski, 2002; Aron, Norman, Aron, McKenna, \& Heyman, 2000; Boothby, Smith, Clark, \& Bargh, 2017); I predict that FOMO will have the strongest effect for an experience in which those with strong stronger ties are involved (i.e., close friends), rather than weaker ties (i.e., acquaintances). Additionally, for this reason, I believe that consumers will be more willing to spend their time and money with strong social ties than weak social ties. More formally: 
H1: Purchase intent will be higher when individuals with whom a consumer has strong ties, as opposed to weak ties, are involved in an activity.

H2: $\quad$ FOMO will be higher when individuals with whom a consumer has strong ties, as opposed to weak ties, are involved in an activity.

In order to test my intuition that FOMO is the fear of regret, I expect that FOMO will be experienced prior to anticipated regret for a future event. This way FOMO and anticipated regret will be serial mediators for the relationship between tie strength and purchase intent. I do not expect to find that anticipated regret will happen before FOMO. More specifically:

H3: $\quad F O M O$ and anticipated regret will be serial mediators to the relationship between tie strength and purchase intent.

H3a: FOMO will be the first mediator and lead to anticipated regret.

H3b: Anticipated regret will be the second mediator and will not lead to FOMO.

Additionally, I propose that the amount of FOMO sustained will vary by the type of experience. Because experiences have a social value (Van Boven, 2005) and help cultivate social connections (Gilovich et al., 2015), I believe that individuals will feel more FOMO for an extraordinary experience with those with whom they share a stronger connection than for an ordinary experience. I believe this would happen due to the overall importance people place on building memories of extraordinary experiences with loved ones and the importance people place on extraordinary experiences which can add to one's personal growth (Bhattacharjee \& Mogilner, 2013). More specifically, when an experience is extraordinary (ordinary), I hypothesize that consumers will show higher purchase intent due to higher (lower) FOMO. I expect to see no differences in FOMO levels for an ordinary experience between social ties because although ordinary 
experiences collectively add to one's overall wellbeing, this happens when people know how to appreciate these moments. In other words, type of experience will moderate the effect of tie strength on purchase intent through FOMO.

H4: The type of experience (ordinary vs. extraordinary) will moderate the relationship between tie strength and FOMO.

H4a: When an experience is extraordinary, FOMO will be higher when one's strong, rather than the weak, social ties are attending.

H4b: When an experience is ordinary, there will be no significant difference in FOMO between strong or weak social ties.

Although it is tempting to think of FOMO and anticipated regret as synonyms, I argue that these are two separate constructs that work through similar processes. Specifically, I believe that FOMO is more focused on the social aspect of an event while anticipated regret focuses more on the actual choice and the missed experience and less on those that are attending. Because consumers are seen to want to collect experiences, I believe that anticipated regret is closely related to gaining collectable experiences. More formally:

H5: Anticipated regret (FOMO) is less (more) associated to the social component of an event.

H5a: Anticipated regret will not mediate the relationship between social ties and purchase intent.

H5b: When an experience is extraordinary (ordinary), consumers will experience more (less) anticipated regret for missing the event.

Finally, none of the previous work on FOMO has addressed the question of whether FOMO is an automatic process or a non-automatic process. According to Dijksterhuis (2007), psychological processes are neither fully automatic or fully 
controlled, I believe that FOMO is more of an automatic process than controlled. In other words, do consumers give the feeling of FOMO deep thought before experiencing or does it happen spontaneously? I believe that FOMO is an automatic process. Formally:

H6: $\quad$ FOMO is an automatic process that happens without careful consideration of the situational factors.

I first looked into the construct of FOMO through qualitative research in order to inform my hypotheses. Because there is limited research on FOMO and experiential consumption from a CB perspective, two focus group sessions enabled me to understand further how the concept of FOMO works in regard to consumer decisionmaking. After the hypotheses were developed, I continued to explore this construct through quantitative research, including a behavioral study to test the FOMO phenomenon on a real consumer decision, resulting in a mixed methods research. The following section provides an overview of the research plan.

\subsection{Overview of studies}

This dissertation includes one qualitative study and four quantitative studies in order to understand the situational variables that lead to high levels of FOMO and thus, higher anticipated regret and purchase intent. As FOMO is a relatively new topic in the consumer behavior literature, I first sought to explore FOMO in depth through a focus group. In study 1, two focus group sessions were conducted to understand how participants describe and discuss FOMO and to see if perhaps FOMO, knowingly or unknowingly, influenced them to make real purchase decisions as I predict in my hypotheses. The primary objective of study 2 was to provide an initial assessment of one of our proposed antecedents to FOMO, the tie strength (strong, weak) that consumers share with the social group participating in a given activity. I assessed whether strong 
social ties, rather than weak social ties, lead to greater purchase intent $(\mathrm{H} 1)$ for an activity due to FOMO (H2 and $\mathrm{H} 3)$. In study 2, I also explore anticipated regret as an outcome of FOMO and test the serial mediation of FOMO and anticipated regret on the relationship between social ties to purchase intent $(\mathrm{H} 3)$. Study 3 tests the type of experience (ordinary, extraordinary) as another proposed antecedent to FOMO. More specifically, I posit that when strong social ties are attending and the experience is extraordinary, consumers will feel more FOMO than when an experience is ordinary (H4). In study 4, I observe whether FOMO is an automatic or a non-automatic process (H6). In study 5, a behavioral study, I test FOMO involving a real consumer decision which participants believe to have a real behavioral consequence $(\mathrm{H} 1$ and $\mathrm{H} 2)$. In this study, I explore whether FOMO forms at least part of the reason consumers attend an event. 
CHAPTER IX. STUDY 1 - FOCUS GROUPS 


\subsection{Methodology}

In order to understand the concept of FOMO further, I decided to first conduct a qualitative focus group. The goal of this study was to find out whether participants ever spent resources of time and money because of FOMO and to identify any potential antecedents or consequences of FOMO. The methodology used for this study followed a series of steps: (1) two formal focus group sessions with undergraduate students, (2) transcription and coding using qualitative data analysis software, (3) identification and analysis of responses, and (4) construction of conceptual model. This kind of qualitative analysis is used in various areas of social science, and while it has its limitations, it is convenient for concept development and the forming of theoretical models (Cresswell, 2012).

The focus groups took place at a southeastern university on the same day, one following the other and lasting an hour each. Participants were recruited online through the college's research subject pool to participate in the study for extra credit. The first session consisted of 5 participants ( 4 females, 1 male). The second focus group also had 5 participants ( 3 females, 2 males). The style of the focus groups was conversational but a series of questions were prepared ahead of time to guide the sessions with follow up questions asked as needed. The following are some of the questions that were asked: (1) what does FOMO mean to you? (2) How important is it for you to not miss out? (3) What kind of situations make you feel FOMO the most? (4) Have you ever gone out when you did not want to because of FOMO? (5) Have you ever spent money because of FOMO?

After the focus groups concluded, the data from audio recording was transcribed verbatim using Rev transcription services. The transcription was then read to obtain a sense of the whole, overall picture. Next, the coding process began through which the 
data was classified in groups pertaining to the reoccurring themes of the discussion from the questions described above. The coding process was aided through the use of Nvivo, a coding software program designed to assist in the analysis of qualitative data.

\subsection{Results}

The analysis provided several insights into the circumstances that lead to FOMO and how individuals tend to feel about FOMO. A word frequency query was first used to determine the most frequently mentioned words; feel, FOMO, think, missing, and friends appeared as some of the most recurring words (see appendix A). The following themes correspond to some of our research questions.

Reluctance to admitting experiencing FOMO

Participants at first were hesitant to admit that they ever felt FOMO. One participant mentioned that she used to feel FOMO sometimes but now she had matured and no longer experienced feeling this way (FG1). Two participants completely denied ever feeling this way; however, when other participants started opening up and admitted to having experienced FOMO in the past, the other two participants expressed that they have also felt this way. This overall reluctance or apprehension to openly admitting feeling FOMO suggests that FOMO is not viewed positively by themselves and others.

\section{Exciting and extraordinary experiences}

When it came to more detailed explanations about the circumstances that caused them FOMO, one participant revealed that it was important to not miss out on opportunities to hang-out with her friends because they went away to different universities and were rarely in town: "Yeah. I wouldn't miss out on something like that, something exciting to me that's exciting... Also obviously things like concerts is super exciting..." (FG2). Others revealed that for some special occasions (i.e., a specific bar 
crawl, or an exciting event) they make the time to not miss out on those events because they are more uncommon or extraordinary.

FOMO is closely related to friends and family

The topic of social media came up and a participant shared feeling FOMO for instance if she was in the library studying and saw someone on social media currently at the beach on a nice day. Further questions inquired whether it would be the same feeling of FOMO for a friend or that acquaintance at the beach: "No. It feels what, more like... I mean those are people that you don't really know." When I asked about feeling FOMO simply because of social comparisons that this acquaintance was at the beach, the participant replied: "Well, I mean, it's not to the same extent, I guess. Okay. Because it's like, oh l'd like to be at the beach but it's not like, l'd like to be at the beach with them" (FG2).

When categorizing the data into themes, the theme for friendships and social ties was the one with the most extensive references in the data. One participant exclaimed: “Um, I think my friends are my biggest ... Like, well, not my biggest but one of my biggest um, values, priorities, I guess, you could say" (FG2). This participant shared an account of when she felt a great deal of FOMO:

"I have a story just because I was working like last summer... and I didn't feel like I could ask my boss also like for the day off, like so last minute, which I was upset at my friend about. Because she planned like this whole scavenger hunt thing that she had been talking about for years... and I felt almost regretful and this is bad but I kind of regret not calling out because I've never done it. And I know so many people call out for so many like honestly selfish reason. But for mine, it was like, I was really upset that I wasn't there for that friend on her birthday. Obviously, I felt like I missed out but to me... she's my best friend, so it was mostly like missing out on that memory with her" (FG2).

There was also an emphasis placed on creation memories with friends and being able to relive them afterwards in future conversation: "When I think of FOMO, I only think 
of missing out on the memories. Because I can always go back on the memories and laugh with my friends. "Remember when we did this?" But when I'm the outsider, it's just like, "All right" (FG2).

\section{FOMO as an antecedent to regret}

Participants occasionally mentioned feeling regretful about missing certain events and were inquired about this construct and how it relates to FOMO: "Like FOMO's usually before like if you're texting or something maybe. Like I don't know. It's like, "Oh, I have the fear of missing out, so let me know." I don't describe the feeling after as FOMO, I describe it as like regret. Literally, I am fearful of missing out when I'm deciding' (FG2). Once the decision has been made, she goes on to explain, feeling FOMO is more of a choice, but regret is what can happen afterwards.

FOMO is high when individuals cannot attend an event

Participants admitted to feeling the most FOMO in situations where they are tied down by obligations such as work: "When I'm at work and other people are out having fun, you compare what you are doing with their experience at the moment" (RG1). They also felt FOMO when they were studying in the library on a beautiful day and then saw pictures of someone on the beach having fun.

Participants also revealed that in order to avoid feeling FOMO, they make sure to plan ahead and make time for their social activities because when you are part of the activity you don't feel FOMO: “Most things, I won't miss out on, to be honest. No. Like I will not, like I won't prioritize school but I'll plan ahead. So, I won't have fear of missing out" (FG2).

\section{Attending undesired events for friends}

While many participants said they did not attend events they did not have an interest in, some participants admitted to feeling social or pressured themselves to 
attend these events because everyone else was going so they should go. Some participants also expressed feeling more obligated to go when there were friends they would not see often. One participant revealed trying something new because of FOMO: "I'm not really an art person - but we went to Painting with a Twist. I went to be with the people, but I wouldn't do it again" (FG2). The participant did not regret the experience but was certain she would not attend again.

FOMO and spending behavior

Most participants admitted to spending money on experiences because of FOMO. "Because I wanted to go and I didn't wanna miss out? Um, yeah. And, and it's crazy, one day, it was like a group of my friends and like their boyfriends. We went to Food and Wine for Disney... I bought my ticket. Two different tickets, spent like $\$ 300$. Now, I'm an annual pass holder, so I always go to Disney" (FG2). Others revealed going to cruises with a group of friends because they did not want to miss out on the experience. Some involved buying clothing items on sale because they were afraid of it not being there again, and finally there was a mention of purchasing an iPhone to stay connected and have one like everyone else.

Other themes that came up once or twice were fear of not getting invited again by a particular social group if one constantly rejects invitations, social media being an important tool to for FOMO, etc. The focus groups were used to provide some additional insights into the constructs and to elaborate on the model development. With this information, it is my intuition that close friends and rare, exciting experiences can result in feeling high FOMO in the majority of consumers.

\subsection{Mind map}

After identifying the common themes, a mind map was developed to in order to visually illustrate the connections between the themes (see figure 3). The purpose of this 
mind map was to make observations that could assist my hypotheses. The underlying themes from the focus groups, although broad, essentially support my hypotheses regarding tie strength and experiences.

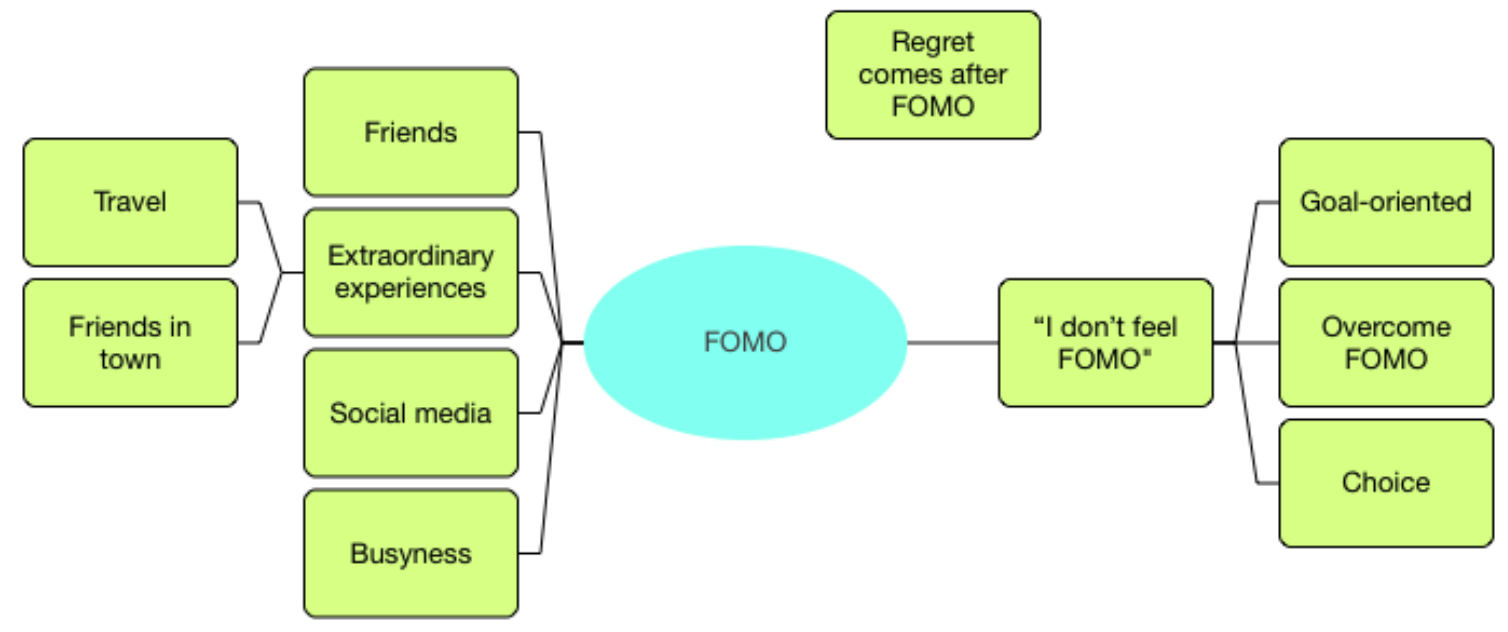

Figure 4. Mind map 
CHAPTER X. STUDY 2 - SERIAL MEDIATION 


\subsection{Introduction}

For the initial empirical study, I test the relationship between social ties (strong, weak) and purchase intention through FOMO by presenting participants with a hypothetical social event taking place in the near future. $\mathrm{H} 1$ proposes that there is a direct effect of tie strength between social groups on purchase intent. I expect that strong social ties should result in higher purchase intent than weak social ties. H2 proposes that strong ties will yield higher FOMO than weak ties. H3 proposes that FOMO and anticipated regret mediate the relationship between social group and purchase intention, with FOMO being an antecedent to anticipated regret $(\mathrm{H} 3 \mathrm{a})$ and not vice-versa $(\mathrm{H} 3 \mathrm{~b})$.

\subsection{Methodology}

The study used a single factor, between participants design (social ties) with two conditions (strong, weak). Two hundred participants from Amazon Mechanical Turk $($ females $=119$, males $=80 ;$ ages $19-75$, average age 36$)$ were recruited for monetary compensation.

Participants were first asked to read a hypothetical scenario. Depending on condition, participants were instructed to imagine that either their close friends (i.e., strong ties) or colleagues that they don't know very well (i.e., weak ties) were going to the movies. Please see below:

“Imagine that your closest friends (colleagues that you don't know very well) are planning on going to the movies this weekend. The movie is said to be a top box office hit, and they are planning to watch it at a special theatre with reclining seats, where food, wine and beer is served for your convenience. You are considering whether to attend or not." 
Following the manipulation, participants completed a 4-item manipulation check for tie strength originally developed by Mittal, Huppertz, and Khare (2008) and slightly adjusted to fit the context of this study (see Appendix B). The tie strength measure answered questions like: How close, would you say, you are to the group of people going to this event? ( $1=$ "Not at all close," 7 = "Very close"). Participants then completed a FOMO measure developed by Przybylski et al., (2013) slightly adjusted for the purpose of this dissertation (see Appendix C). Following the FOMO scale, participants completed an anticipated regret measure from Zeelenberg, van Dijk, Manstead \& der Plight (1998) adjusted for this research (see Appendix D). Purchase intent was indicated on a 7 -point Likert scale ( $1=$ extremely unlikely to $7=$ extremely likely) by answering the question: How likely or unlikely are you to purchase a ticket to this event with this particular social group? One final measure was used to check whether participants perceived the event differently or not based on the social ties condition; therefore, participants were asked: Please specify the degree to which you believe this movie outing to be ordinary or extraordinary ( 1 = extremely ordinary, 7 = extremely extraordinary). Finally, demographic questions were answered, and participants were thanked for their time.

\subsection{Results}

Manipulation checks. A manipulation check was included to ensure that participants in the strong (weak) tie condition were thinking about their close friends (students at their university). An independent samples t-test revealed that there was a significant difference between participants in the strong ties condition $(M=5.97, S D=$ 1.08) and the weak ties condition $(M=2.97, S D=1.48) ; t(198)=-16.38, p<.05$, as expected. Specifically, more participants in the strong (weak) tie condition reported thinking about their closest friends (students at their university) throughout the study. 
Since the hypothetical event was described in the same way across conditions, I included a measure to rule out that the type of social tie influenced how ordinary or extraordinary the experience was perceived to be. The overall results revealed that, overall, the event was perceived as neither ordinary nor extraordinary on a 7-point Likert scale $(M=4.61, S D=1.49)$, as participants rated this experience to be at a midpoint. An independent samples t-test was conducted to ensure that there were no differences in the ordinariness of the event by the tie strength condition. The results; however, did reveal that there was a significant difference between conditions in their belief about the ordinariness or extraordinariness of the event $\left(M_{\text {strong-ties }}=4.96, S D=1.26\right.$ and $M_{\text {weak-ties }}=$ 4.25, $S D=1.63, t(198)=-3.45, p<.05)$.

A one sample t-test was used to see whether each tie strength condition differed from the midpoint (4) on the level of ordinariness or extraordinariness participants perceived the experience to be. While the weak tie strength condition did not revealed a significant difference to the midpoint $t(98)=1.55, p=.13(M=4.25, S D=1.63)$, the strong tie strength condition did reveal a significant difference to the midpoint $t(100)=$ $7.68, p<.05(M=4.96, S D=1.26)$. This suggests that at least for the strong ties condition, participants perceived the experience to be slightly more extraordinary.

Purchase intent. In order to examine the effect of social tie (strong, weak) on purchase intent, I conducted an independent samples t-test. The analysis revealed a significant difference between tie strength for purchase intent $t(148)=-7.16, p<.05$. Specifically, as anticipated in $\mathrm{H} 1$, participants in the strong ties condition $\left(M_{\text {strong-ties }}=\right.$ $5.81, S D=1.43)$ reported higher purchase intent compared to participants in the weak ties condition $\left(M_{\text {weak-ties }}=4.32, S D=1.81\right)$.

FOMO. The findings of an independent samples T-test indicate that there were significant differences between social ties conditions on the levels of FOMO 
experienced. Participants in the strong ties condition indicated feeling higher FOMO $\left(M_{\text {strong-ties }}=3.98, S D=1.49\right)$ than participants in the weak social ties condition $\left(M_{\text {weak-ties }}\right.$ $=3.53, S D=1.29), t(198)=-2.26, p<.05)$ consistent with $\mathrm{H} 2$.

Serial Mediation Analysis. To test the mediating role of FOMO and anticipated regret on the direct effect of social ties to purchase intent, a mediation analysis $(10,000$ resamples; PROCESS model 6) was conducted (Preacher \& Hayes 2008; Preacher, Rucker, and Hayes 2007). This indirect effect of FOMO (M1) and anticipated regret (M2) from tie strength to purchase intent was statistically significant, as revealed by a $95 \%$ Bootstrap confidence interval that is entirely above zero $b=.15, \mathrm{SE}=.08,95 \% \mathrm{Cl}$ $[.02, .34]$. These results indicate that the effect of social groups on purchase intent is mediated by FOMO and anticipated regret consistent with $\mathrm{H} 3$. When a strong social tie is involved in an experience, people tend to feel more FOMO, which then leads to anticipated regret and finally to higher purchase intent for the upcoming event.

In order to test $\mathrm{H} 3 \mathrm{a}$ and $\mathrm{H} 3 \mathrm{~b}$ which states that $\mathrm{FOMO}$ is an antecedent to anticipated regret, a serial mediation (10,000 resamples; PROCESS model 6) was conducted with anticipated regret as the first mediator (M1) and FOMO as the second serial mediator (M2). The results indicate that the serial mediation with $\mathrm{M} 1=$ anticipated regret and M2 = FOMO was not significant as seen by $95 \%$ Bootstrap confidence interval that crosses zero $b=.03, \mathrm{SE}=.04,95 \% \mathrm{Cl}[-.04, .13]$ which is consistent with $\mathrm{H} 3 \mathrm{a}$ and $\mathrm{H} 3 \mathrm{~b}$. This strengthens my argument that FOMO is the fear or regret and thus is experienced before any kind of regret. 


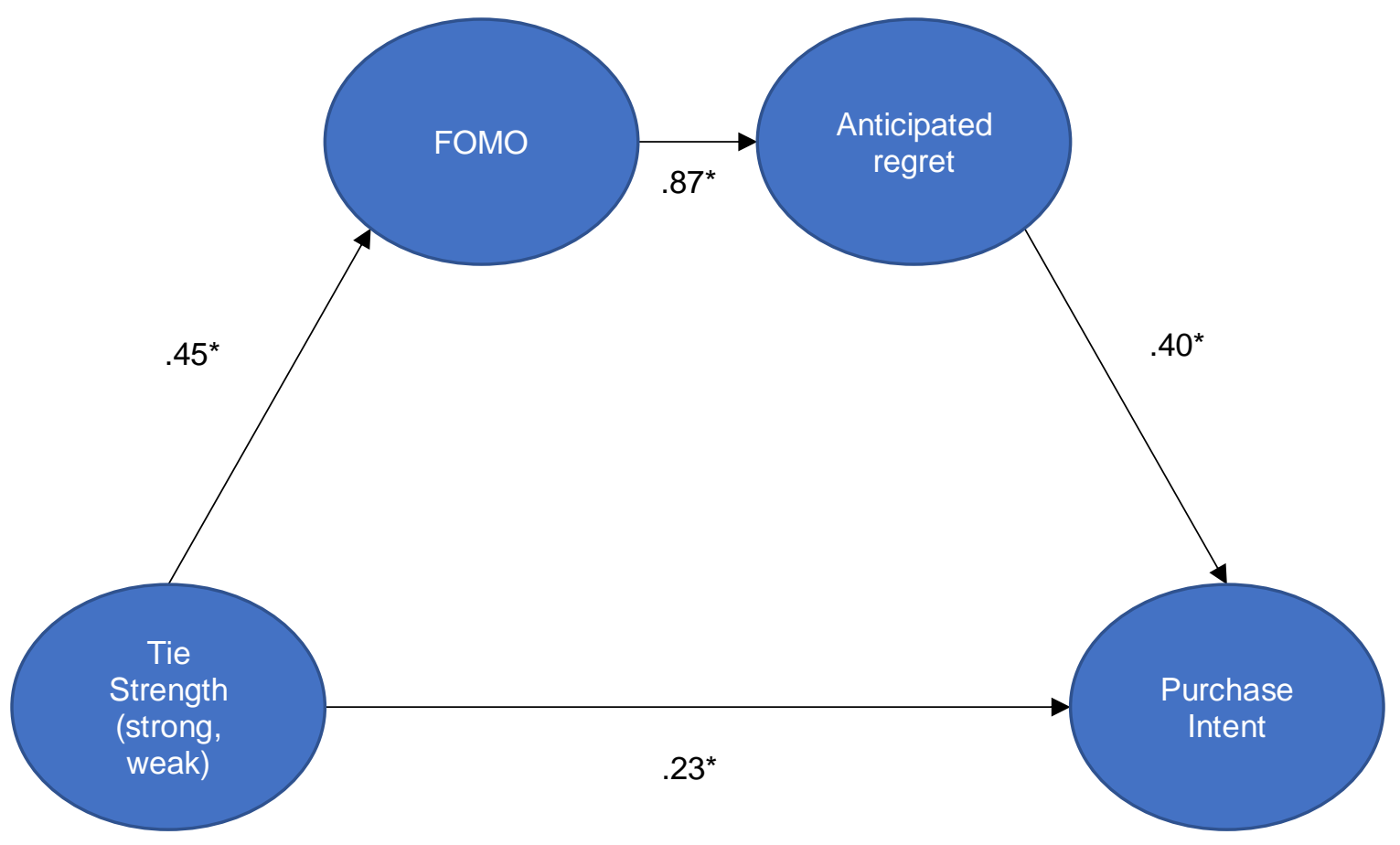

Figure 5. Serial mediation results

\subsection{Discussion}

Study 2 provides support for Hypotheses 1 and 2, the influence of social groups on purchase intent through FOMO. Participants anticipated feeling higher FOMO when a strong social tie was involved than a weak one (Hypothesis 1). Participants were more willing to purchase a ticket to the movies if they knew that their close friends, as opposed to colleagues whom they did not know so well, were attending (Hypothesis 1). FOMO and anticipated regret mediate the relationship between social groups and purchase intent (Hypothesis 2). The results provide preliminary evidence that strong social ties lead to greater FOMO and anticipated regret, which lead to greater purchase intent, than weak social ties. 
CHAPTER XI. STUDY 3 - SERIAL MODERATED MEDIATION 


\subsection{Introduction}

In the previous study, I explored the effects of tie strength on FOMO and purchase intent, yet the type of experience was not manipulated. I build on these findings in Study 3 by introducing the role of the experience type on FOMO. More specifically, I manipulate extraordinary versus ordinary experiences to test my hypotheses about their effects on FOMO.

Study 3 tested H4 regarding which type of experience (i.e., ordinary or extraordinary) is capable of causing more FOMO between the social groups (i.e., strong or weak). The purpose of this study was to test that an extraordinary experience will result in higher FOMO $(\mathrm{H} 4 \mathrm{a})$ than an ordinary experience for strong social ties than for weak social ties $(\mathrm{H} 4 \mathrm{~b})$, as hypothesized. Due to the closer bond shared with close friends, and the intuition that close people want to share extraordinary experiences with a closer social group, I expect that when an experience is extraordinary, strong social ties will feel more FOMO than weak social ties. I also expect that when an experience is ordinary, consumers will anticipate similar levels of FOMO regardless of whether the event will be attended by strong or weak social ties Another purpose of this study is to empirically demonstrate that FOMO is an antecedent to anticipated regret $(\mathrm{H} 5)$. I expect that FOMO is more closely related to the social aspect of an event than anticipated regret $(\mathrm{H} 5 \mathrm{~b})$, and that anticipated regret is more closely tied to the experience itself. I expect that when an experience is extraordinary, consumers will feel more anticipated regret than when an experience is ordinary $(\mathrm{H} 5 \mathrm{~b})$. 


\subsection{Methodology}

The study used a 2 (tie strength: weak, strong) x 2 (experience: ordinary, extraordinary) between-participants design. One hundred and twenty nine ${ }^{1}$ undergraduate participants (females $=70$, males $=59 ;$ ages $18-45$, average age $=23$ ) from a southeastern university participated in exchange for extra credit.

Participants were asked to imagine a scenario in which their friends (strong social ties) or students at their university (weak social ties) were going to a local music festival. I also varied the descriptions of the local music festival such that one condition made the event appear more exclusive and unique (extraordinary experience), while the other made it appear more common and frequent (ordinary experience). The scenarios used in the study can be seen below:

\section{Ordinary Experience}

Imagine that you have the opportunity to go to a local music festival where a band you're not familiar with will be playing. You don't know any of their songs and this band performs often in your city. A promoter offers you general admission tickets, which are offered to everyone, for a reasonable price.

\section{Extraordinary Experience}

Imagine that you have the opportunity to go to a local music festival where your favorite band will be playing. This band rarely goes on tour and they are performing in your city. A promoter offers you VIP tickets with backstage passes to meet the band, which are very limited, for a reasonable price.

\footnotetext{
${ }^{1}$ Eight participants of 129 failed an attention check and were excluded from the analysis.
} 
Next, participants read that either their close friends (strong ties condition) or students at their university who they do not know well (weak ties condition) were planning to attend the local music festival. Specifically, participants read one of the following sentences related to the social group that would be attending the music festival: You know that your closest friends (students at your university that you don't know well) were planning on going to this event and had recently purchased their tickets.

After reading the scenario, participants answered the question: "How likely or unlikely are you to purchase a ticket to this event? on a 7-point Likert scale $(1=$ extremely unlikely, 7 = extremely likely). Participants then completed the same FOMO scale (Przybylski et al. 2013) as used in Study 2, as well as an anticipated regret measure (Zeelenberg, van Dijk, Manstead \& der Plight, 1998). A manipulation check for the type of experience was also used in the study; participants were asked to please indicate to what extent they believed the experience to be ordinary or extraordinary $(1=$ extremely ordinary, $7=$ extremely extraordinary). Participants then completed an attention check. A covariate measure was taken to control for any effect of general liking of music festivals "Please indicate how much you like or dislike music festivals in general" ( 1 = Dislike a great deal, 7 = Like a great deal), but the measure was not used as it did not affect results. Finally, participants answered demographic questions and were thanked for their time.

\subsection{Results}

Pretest. Prior to the main study, a pre-test was conducted to ensure that the selected scenarios did represent an ordinary versus extraordinary experience as desired. To that end, a group of participants $(n=18)$ was exposed to the extraordinary experience manipulation described above and another group of participants $(n=9)$ was 
exposed to the ordinary experience manipulation. Participants were asked to rate to what extent they found the particular experience to be ordinary or extraordinary, using a 7-point Likert scale (1 extremely ordinary, $7=$ extremely extraordinary). An independent sample T-tests was conducted to compare the ordinary and extraordinary event scores between the experience type conditions. There was a significant difference in the scores for ordinary $(M=2.81, S D=1.33)$ and extraordinary $(M=5.20, S D=1.48)$ conditions; $t(24)=-4.28, p<.05$. These results indicate that the conditions were significantly different. Thus, the scenarios were used unedited to represent the ordinary and extraordinary conditions.

Manipulation checks. Moving onto the main study, an independent samples ttest was conducted to compare participants' beliefs on whether the scenario was ordinary or extraordinary to the actual condition to which they were randomly assigned. There was a significant difference in the scores for the ordinary $(M=3.66, S D=1.40)$ and extraordinary experience $(M=5.54, S D=1.23)$ conditions; $t(127)=-8.05, p<.05$ such that, as anticipated, the extraordinary experience was rated as significantly more extraordinary than the ordinary experience.

FOMO. I then conducted a two-way ANOVA to examine the effect of tie strength (strong, weak) and type of experience (ordinary, extraordinary) on FOMO. The analysis yielded a significant interaction between social ties and type of experience $F(1,116)=$ 4.93, $p<.05$. In addition to the interaction effects, there was a main effect for tie strength $F(1,116)=4.74, p<.05)$, such that FOMO was significantly higher for the strong social ties $(M=3.33, S D=1.34)$ than for the weak social ties $(M=2.76, S D=1.24)$. There was no significant main effect of type of experience on FOMO $F(1,116)=.01, p=.93$.) To further elaborate upon the interaction effect, the simple main effects revealed that when an experience is ordinary, there was a significant difference in the amount of FOMO 
reported between conditions, $F(1,116)=10.97, p<.05$ with FOMO being higher when the scenario involved a strong $(M=3.06, S D=.24)$ relative to a weak $(M=2.52, S D=$ .22) social ties, consistent with $\mathrm{H} 2$. However, when an experience was designed to appear extraordinary, FOMO levels between social ties were equally high, revealing no significant difference $F(1,116)=.00, p=.98$.

Anticipated regret. Next, I conducted a two-way ANOVA to examine the effect of tie strength (strong, weak) and type of experience (ordinary, extraordinary) on anticipated regret. Unlike FOMO, the anticipated regret analysis did not reveal a significant interaction between social group and type of experience $F(1,120)=3.37, p=$ .07. However, there was a main effect for type of experience $F(1,120)=23.65, p<.05$ consistent with $\mathrm{H} 5$, such that anticipated regret was significantly higher for the extraordinary experience $(M=4.25, S D=1.26)$ than for the ordinary experience $(M=$ $3.07, S D=1.40$ ) consistent with $\mathrm{H} 5 \mathrm{~b}$, but there was no significant main effect of social group $F(1,120)=.87, p=.35$ consistent with $\mathrm{H} 4 \mathrm{~b}$. Together, these findings suggest that anticipated regret and FOMO are distinct processes. FOMO has a significant main effect for social groups but not for the type of experience, whereas anticipated regret has a significant main effect for the type of experience but does not have a significant main effect for the social component of the social group.

Purchase intention. I then ran a two-way ANOVA to examine the effect of tie strength (strong, weak) and type of experience (ordinary, extraordinary) on purchase intention. There was no significant interaction between social group and type of experience $F(1,122)=.01, p=.94$ for purchase intention. It did, however, reveal a significant main effect for tie strength $F(1,122)=4.67, p<.05$, such that purchase intention was significantly higher when a strong social tie $(M=4.87, S D=1.42)$ participated in the experience than when a weak social tie $(M=4.42, S D=1.26)$ 
participated. There was also a significant main effect for the type of experience $F(1$, $122)=.32 .63, p<.05$ such that purchase intention was higher for an extraordinary experience $(M=4.25, S D=1.26)$ than for an ordinary experience $(M=4.25, S D=1.26)$. Please see Figure 3 below.
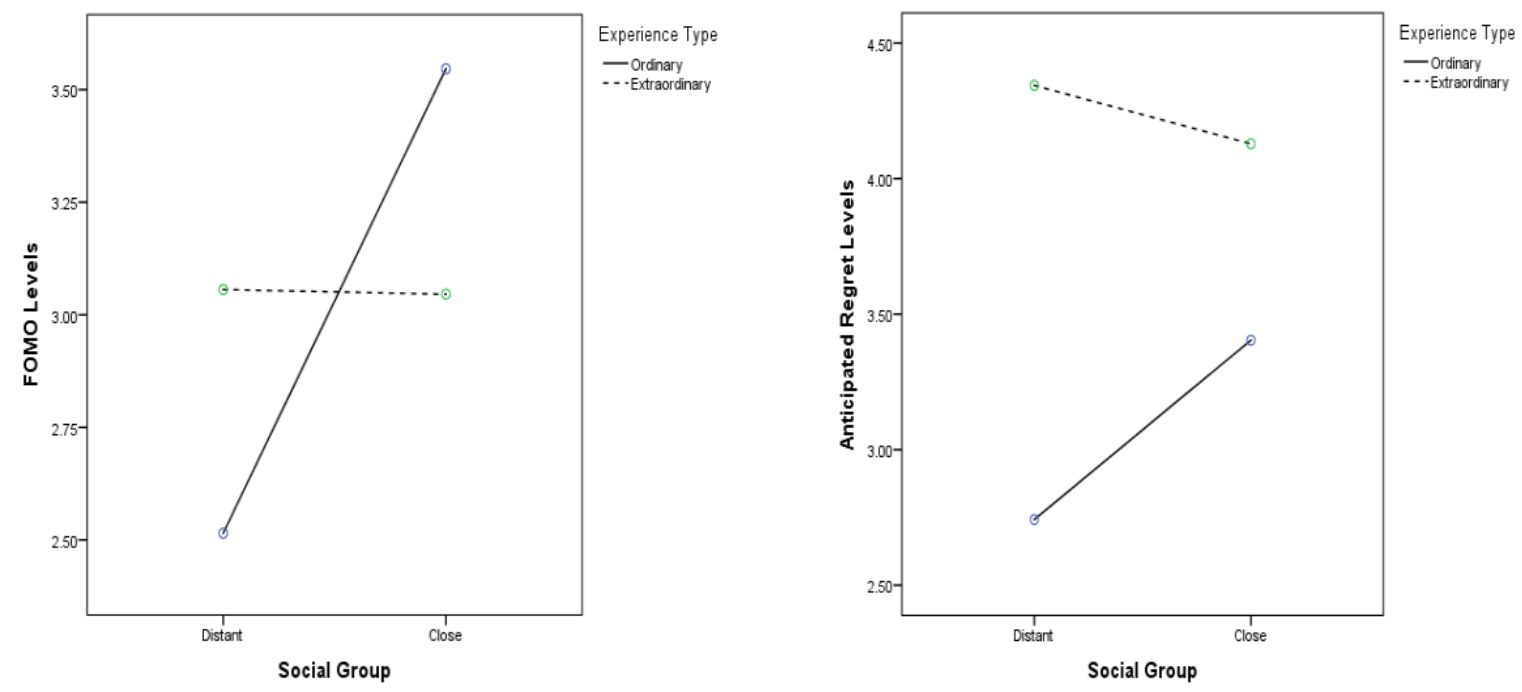

Figure 6. FOMO and anticipated regret as dependent variables

Serial Moderated Mediation. A moderated mediation analysis $(10,000$ resamples; PROCESS model 86) tested the moderating role of type of experience on the indirect effect of tie strength to purchase intention through FOMO and anticipated regret (Preacher \& Hayes 2008; Preacher, Rucker, and Hayes 2007). Results reveal that this conditional indirect effect is statistically different from zero, as revealed by a $95 \%$ Bootstrap confidence interval that is entirely below zero $(b=-.34, \mathrm{SE}=.14,95 \% \mathrm{Cl}$ [-.64, -.08]), indicating a significant serial moderated mediation. Additional examination of the conditional indirect effects indicated significant mediation for ordinary experience $(b=.29, \mathrm{SE}=.11, p<.05,95 \% \mathrm{Cl}[.11, .52])$ but not for extraordinary experiences $(b=$ 
$-.04, \mathrm{SE}=.09, p<.05,95 \% \mathrm{Cl}[-.23, .14])$. This indicates that our proposed serial moderated mediation model works supporting hypothesis 3; however, our prediction that extraordinary experiences will yield higher FOMO for strong and weak social ties $(\mathrm{H} 3 \mathrm{a})$ and that there will be no differences between social tie strength for ordinary conditions $(\mathrm{H} 3 \mathrm{~b})$ are not supported. In fact, the results indicate that it is when an experience is ordinary that FOMO levels will be higher for close social groups only which means that our hypotheses $\mathrm{H} 3 \mathrm{a}$ and $\mathrm{H} 3 \mathrm{~b}$ were partially supported - in that there was an interaction - but the hypothesized direction of the effect was not supported and was actually in the opposite direction.

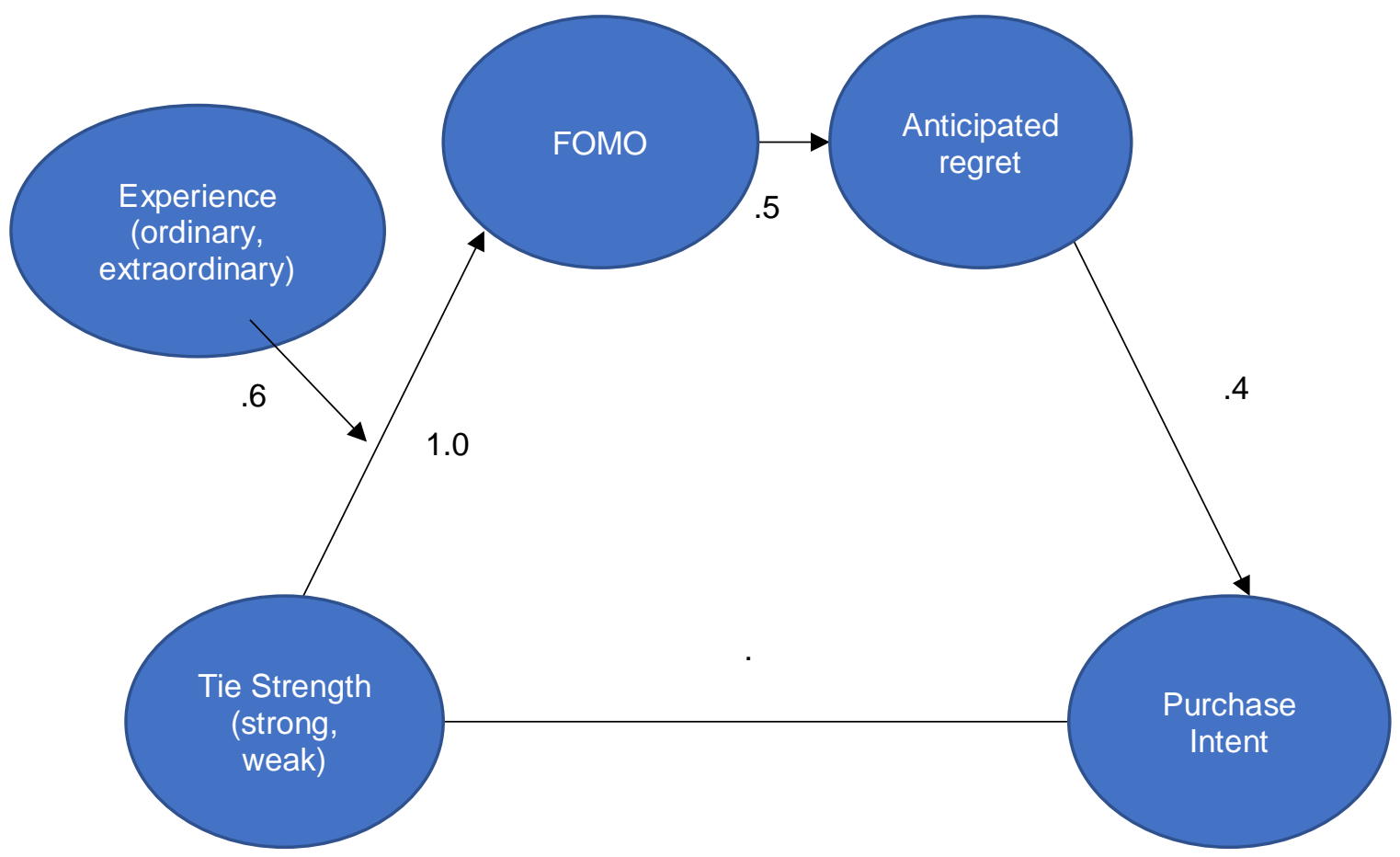

Figure 7. Serial moderated mediation results 
Variance explained. A series of regressions where conducted in order to determine the additional predictive power FOMO adds beyond merely using regret in the model. A Hayes regression (model 86) was used to test my serial moderated model from tie strength to purchase intent through FOMO and anticipated regret moderated by type of experience. As seen above, the moderation was significant $b=1.83, t(110), p<.05$. A significant regression was found $F(5,110)=16.23, p<.05$, with an $R^{2}$ of .42 .

I then proceeded to test the model without FOMO to determine whether this change would reflect a lower explained variance for the overall mode. Using a Hayes regression (model 7) I tested the relationship between tie strength to purchase intent through anticipated regret and moderated by type of experience. The moderation was significant $b=1.93, t(120), p<.05$. A significant regression was found $F(2,110)=32.48$, $p<.05$, with an $R^{2}$ of .35 . These results indicate that FOMO's incorporation into the model raises the power from .35 to $.42 \mathrm{R}^{2}$.

\subsection{Discussion}

In this study, I observed the effects of ordinary and extraordinary experiences on FOMO and anticipated regret, for strong and weak social ties, resulting in purchase intention. I found that there was an interaction between the type of experience and the social group on FOMO, which then led to anticipated regret and finally to purchase intention. Specifically, for ordinary events, FOMO was higher for strong social ties than for distant others. I also observed whether FOMO and anticipated regret operated in the same manner and whether they were essentially the same construct. The lack of interaction between tie strength and type of experience on anticipated regret indicates that anticipated regret is different from FOMO which revealed a significant interaction with the same antecedents. When looking further in to the results, there was a main effect for type of experience on anticipated regret but there was no main effect for tie 
strength which supports my intuition that FOMO is much more of a social construct than anticipated regret. FOMO on the other hand saw a strong main effect for tie strength. As predicted, the results indicated that FOMO and anticipated regret are different constructs that can happen simultaneously through different mechanisms. While FOMO closely tied to social implications, it has been seen to be an antecedent to anticipated regret in this research, strengthening my argument that FOMO is the fear of regret. 
CHAPTER XII. STUDY 4 - AUTOMATICITY 


\subsection{Introduction}

The past studies aimed to find differences in FOMO levels between groups of opposing social tie strength. This study only considers strong ties, the group causing greater FOMO, to further understand the workings of this phenomenon. More specifically, I use strong ties to explore differences in automaticity to see whether FOMO happens automatically or after careful consideration. I expect to find that FOMO happens in a more automatic manner and the effect lessens after careful consideration in most individuals $(\mathrm{H} 6)$.

\subsection{Methodology}

The study was a single factor (automaticity) 2 cell (automatic, controlled) between participants design. Three hundred and seventy-five participants were recruited $($ females $=218$, males $=156$, two participants failed to report their sex $($ ages 18-88, average age $=38$ ) from Amazon Mechanical Turk for monetary compensation.

Participants were first given a specific set of instructions developed by Aaker and Briley (2006) on how to answer the questions in the study depending on their condition and were asked to read them carefully. Participants in the automatic condition read: Please respond with your "natural, automatic impulses" and draw on your "initial reactions" when answering questions about the scenario. While participants in the controlled condition were asked: Please respond with your "mindful, elaborated

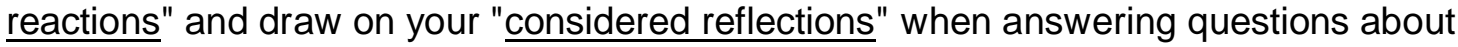
the scenario. These instructions were given again before participants read the hypothetical event and before they answered the FOMO measure.

After carefully reading the instructions, participants were given the following hypothetical scenario to read: 
"Imagine that you are scrolling through your social media feed and you see that your closest friends are having dinner at a trendy restaurant that recently opened. They look like they are having a great time catching up over a nice meal. Most of your friends are there, but for some unforeseen reason, you were unable to make it."

This hypothetical scenario was given to all participants followed by an image simulating a Facebook post for this event (see Appendix E). Then participants were given the FOMO measure to complete used in all previous studies. Participants in the automatic condition were encouraged to answer the questions as quickly as possible and could see a timer counting up the time that they spent on the FOMO questions. Participants in the controlled condition were encouraged to take their time to answer 6 multiple choice questions and were informed that they had 2 minutes to consider their answers before the submit button would become available. This gave participants plenty of time to read and answer the questions carefully. Although there was a timer measuring the time spent on these questions, participants in the controlled condition did not see the timer while answering the FOMO questions.

After participants completed the FOMO measure, two questions were used to determine whether participants had answered as intended by their condition. More specifically, participants were asked to complete the following sentence: "I answered the questions..." (1 = using my initial reactions, 7 = reflecting thoroughly $)$ and $(1=$ responding quickly, $7=$ thinking carefully). Finally, participants were asked demographic questions and were thanked for their time. 


\subsection{Results}

Manipulation checks. An independent samples T-test was conducted in order to determine that the participants in the automatic response condition answered the questions using their initial reactions and that participants in the controlled response condition used their mindful elaborated reactions. The results revealed that there were significant differences between conditions on their scores of how they answered the two manipulation check questions $t(373)=-18.81, p<.05$ with the automatic condition answering on the lower end of the 7-point scale $(M=2.72, S D=2.04)$ and controlled condition answering on the higher end of the scale $(M=6.06, S D=.09)$. Another T-test was used to determine that each condition also differed from the midpoint on how they responded to these questions. The automatic condition revealed a significant difference to the midpoint $t(207)=-9.04, p<.05$ as well as the controlled condition $t(166)=22.619$, $p<.05$ indicating that the manipulation worked as intended.

Furthermore, I measured the time participants spent per condition while answering the FOMO measure. The results reveal that there were significant differences between the automatic and controlled conditions $t(373)=-5.12, p<.05$ with participants in the automatic condition ( $M=28.84)$ answering faster than the controlled condition ( $M$ $=191.25, S D=410.06)$.

FOMO. I then conducted an independent samples T-test to see whether there were any differences in FOMO scores between conditions (automatic, controlled). The results indicate that there were significant differences in FOMO scores by condition $t(373)=2.23, p<.05$ with the automatic condition reporting greater FOMO $(M=4.14$, $S D=1.44)$ than the controlled condition $(M=3.81, S D=1.42)$, supporting $H 6$. 


\subsection{Discussion}

While the first studies of this dissertation attempt to understand the relationship between social ties on purchase intent through FOMO and anticipated regret, the aim of this study was to answer an important question outside of the current model: is FOMO an automatic process or controlled process? The results indicate that FOMO is an automatic process and the effects start to diminish after careful consideration which supports my initial hypothesis on automaticity. 
CHAPTER XIII. STUDY 5 - BEHAVIORAL STUDY 


\subsection{Introduction}

While the effects of FOMO on purchase intent have been strong in our empirical research using hypothetical scenarios, I wanted to see whether FOMO was an important contributing factor to a real consumer decision. The last study is meant to measure FOMO for a free event for students at a local movie theatre (which participants will believe to be real) and see whether participants are willing to attend based on the tie strength he/she shares with another person (i.e., friend or acquaintance) that is going.

\subsection{Methodology}

The study consisted of one factor (tie strength) 2 cell (strong, weak) between participants design, to see the differences in behavior intent to attend a movie event mediated by FOMO. Therefore, for the strong ties condition, 52 participants were intercepted and recruited in a dyad, two at a time, only when two individuals were sitting together. For the weak ties condition, the other 50 participants were intercepted, two at a time, when individuals were sitting alone and introduced, then randomly paired together. During both conditions, individuals were told that they were "partners in this study" then instructed to sit on different tables and given iPads to complete the study. I assigned the condition on the survey before handing participants the iPads. The assumption was that individuals sitting and talking together share a stronger tie than individuals recently introduced. One hundred and two students were recruited (females $=42$, males $=28$; ages $18-34$, average age $=21$ ) from a Southeastern university and were asked to participate in dyads. Fifteen participants reported a tie strength that did not match their condition, so the entire dyad was removed from the study, leading to the elimination of 30 participants.

The cover story consisted of their participation in two separate surveys; the first was a survey on social relationships for $\mathrm{PhD}$ student researchers and the second was a 
survey for the university's event planning organization to get feedback on a current organized event (i.e., the movie event) and for improvement on future ones. Participants were also told that they could RSVP for this free event after the completion of this study. The reason for the cover story was to separate the tie strength measures from the FOMO and behavior intent measures so that participants did not guess the purpose of the study. The event in question was a movie event at a local movie theatre organized by the university's for its students. A specific movie was selected, a documentary by Disneynature called Penguins, that was scheduled to be playing on that week's Friday evening. Prior to the study, movies were pre-tested to make sure that the movie picked would be neither highly desirable to watch or highly undesirable to watch by students (discussed in detail below). Although the specific movie and theater are real, the movie event itself, however, was not real but students were told that it was a real event that would take place later on that week. After the study, participants were debriefed and compensated with an actual movie gift card in order to reduce any disappointment experienced upon realizing the free movie event was not actually real. The $\$ 10$ movie gift card could be used for any movie and time of their choosing without expiration date.

Participants first started with the social relationship survey and were given the same adjusted tie strength measure that was used in study 2 of this dissertation (Mittal, Huppertz, \& Khare, 2008) adjusted to specifically refer to their "partner in the study". Participants ended the first part of the study with demographic questions and were told to raise their hand to let the researcher know they had completed the first study. The researcher would then give them a code to proceed to the next study. There were two researchers appearing to be conducting this study and two participants at a time. For simplicity, I will call the researchers $\mathrm{R} 1$ and $\mathrm{R} 2$, and the participants $\mathrm{P} 1$ and $\mathrm{P} 2$. When the researcher $(\mathrm{R} 2)$ approached participant $(\mathrm{P} 1)$ to enter the code for them, $\mathrm{R} 2$ casually 
informed participants that they had spoken to their partner in the study (P2) and P2 had mentioned that he/she was interested in attending the advertised movie event. The first researcher (R1) gave the code to the other participant (P2) so that both participants could see that both researchers had interacted with their partner in the study at some point. Then both researchers causally asked participants if they were considering attending as well. All participants were told this, although the researchers only first ask after telling the participants that their partner in the study mentioned they would be attending. Since both researchers interacted with participants, participants should infer this statement to be true.

The rest of the questions on the second survey were meant to measure whether the participant would attend the event based on their FOMO because of the tie strength shared with their partner in the study also believed to be attending. The first part of the second survey gave participants information on the movie, Penguins, that would be playing (see Appendix G). After participants saw the image and description of the movie they were asked to rate their likelihood of attending this event on a 7-point Likert scale (1 $=$ extremely unlikely to 7 = extremely likely) by answering the question: How likely or unlikely are you to attend this event? Participants then completed the same adjusted FOMO measure from Przybylski et al., (2013) used in studies 2, 3, and 4. Finally, some covariate measures were taken such as their attitudes for that particular movie genre (1 $=$ dislike a lot, 7 = like a great deal) and how much they are looking forward to seeing this movie $(1=$ not looking forward to it at all, $7=$ looking forward to it a lot). Participants were thanked for their time and debriefed. In the debriefing they were told they would be compensated with a $\$ 10$ Regal movie theatre gift card which was distributed by one of the moderators. 


\subsection{Pretest results}

Pretest. In order to determine which movie would be most appropriate for the study, I conducted a pre-test to determine student's perceptions of some upcoming movies airing at the movies around the time the study would be conducted. Seven movies were picked from various genres including comedy, dramas, thrillers and documentaries. The goal was to pick a moderately interesting movie that not everyone wanted to see or not see. This way the decision to attend has more to do with their partner in the study. To that end, a group of 165 participants were recruited from a southeastern university in exchange for course credit. Participants were shown a picture of the movie ad (poster) and were given a written description to read about the movie along with the director's, actors' and genre information gathered from IMDB.com, the official site for upcoming movies. Participants were asked about their attitudes toward each movie, likelihood of attending for free, purchase intent, and attitudes toward that specific genre. A frequency analysis was used for all the answers and a movie was picked that had the most answers relatively neutral or at the midpoint on a 7-point Likert scale.

\subsection{Main study results}

Manipulation checks. An independent samples T-test was conducted in order to determine that there were significant differences between social ties conditions (strong, weak). The results revealed that there were significant differences between conditions on their scores of tie strength $t(68)=-43.47, p<.05$. with the strong ties condition reporting stronger tie strength $(M=6.47, S D=.73)$ than the weak ties condition $(M=$ $1.12, S D=.29)$. Another T-test was used to determine that each condition also differed from the midpoint (4) on how they responded to these questions. Both conditions revealed significant differences to the midpoint as reflected by the following $t$ tests for the 
strong tie strength condition $t(46)=-48.82, p<.05(M=1.17, S D=.40)$ and for the weak tie strength condition $t(34)=20.36, p<.05(M=6.45, S D=.71)$ indicating that the manipulation worked as intended.

FOMO. I then conducted an independent samples T-test to determine whether scores differed by social ties conditions (strong, weak). The results did not indicate a significant difference in FOMO scores by condition $t(68)=-1.745, p=.086$ with the strong ties condition reporting greater FOMO $(M=3.33, S D=1.26)$ than the weak ties condition $(M=2.75, S D=1.39)$, though results were in the hypothesized direction

Behavior intent. An independent samples T-test was conducted to determine whether there were differences by condition in regard to behavior intent to attend the movie event. The results indicated that there were significant differences between to strong and weak social ties conditions in regards to behavior intent $t(68)=-4.42, p<.05$ with the strong ties condition reporting greater $\mathrm{BI}(M=4.33, S D=1.73)$ than the weak ties condition $(M=2.49, S D=1.68)$. Because I found no significant relationship between tie strength and FOMO, no mediation analysis was conducted.

\subsection{Discussion}

The purpose of this study was to test my past findings in a scenario involving a real decision, thus moving away from the hypothetical nature of previous studies. While the results did not yield a significant interaction for the relationship between tie strength and FOMO, there are several reasons why this pattern of results may have occurred. Firstly, FOMO is a phenomenon that individuals are not always conscious of. Secondly, given that it is a behavioral study and there are a lot of variables that are not being controlled for, this study could have benefitted from a larger sample size. Lastly, the study did not account for previous plans individuals may have had for that specific date 
given which could have decreased the FOMO experienced. In the future, I plan to run this study using a larger sample size to account for these variables. 
CHAPTER XIV CONCLUSION 


\subsection{Extended discussion}

Building on research from other fields on the consequences of FOMO, I proposed an outcome that connects FOMO to the consumer behavior literature as little is known of the ways in which FOMO affects consumers (Hodkidson, 2016). I also provide antecedents that further helps us understand this phenomenon. While past research has viewed FOMO from an individual difference perspective (Al-Menayes 2016; Baker et al. 2016; Collins \& Van Abeele, 2013; Hato 2013; Przybylski 2013; Riordan et al. 2015), I explored situational antecedents to FOMO that had been largely overlooked. Although FOMO can affect consumers differently, I demonstrated that there are situations and circumstances that will lead most consumers to experience FOMO in the context of experiential purchases. These higher FOMO levels, in turn, can lead to downstream consequences like purchase and behavior intention.

Through this dissertation, I contribute to the literature in three ways. First, I explore the underlying mechanisms of a highly popular acronym commonly used in advertising appeals; thus, identifying new antecedents and consequences to FOMO. Second, I differentiate and relate FOMO to pertinent constructs such as anticipated regret, addressing the relationship between the two. Third, I fuel the conversation on FOMO and its effect on consumers and invite future research on this topic. FOMO has been posited as the reason behind mobile checking behavior and high social media usage (Przybylski et al., 2013), FOMO must then have the potential to affect consumers on a daily basis, as the average American spends about three hours and 43 minutes a day on mobile devices this year (Pesce, 2019) and, in some instances, while driving (DMV.org).

Through focus group sessions, I learned that people do in fact make behavioral decisions for trips, concerts, and parties due to FOMO. This supports previous research 
suggestions that FOMO may be the reason behind increased adventure tourism (Torres, 2016). In a more generalizable context, this research suggests that FOMO can lead individuals to part with their resources of time and money in order to not miss out on experiences with their friends and family.

My dissertation suggests that different social groups, particularly the tie strength they share with them, partaking in an upcoming event affect FOMO levels differently, with strong ties being the social group that can lead to higher levels of FOMO for most individuals. These insights had not been previously recorded in the literature; therefore, this dissertation provides a foundation for future research on FOMO. These findings also contribute to the tie strength literature. Furthermore, I link tie strength to higher purchase intention for experiential consumption which reinforces my claim that $\mathrm{FOMO}$ is affecting consumer behavior in various ways. For instance, in situations in which one's friends (i.e., strong social ties) are partaking in a social event, consumers tend to feel higher levels of FOMO should they not attend than if acquaintances (i.e., weak ties) were partaking in the event.

Consumers are also more willing to purchase tickets for a social situation that their close friends rather than acquaintances are attending, with FOMO mediating this effect. FOMO is widely defined in the literature as a "pervasive apprehension that others may be having rewarding experiences from which one is absent," (Przybylski et al., 2013 , p. 1841) yet this is the first research that specifically confirms which "others" tend to cause people to experience greater levels of FOMO. This distinction is important because the construct of FOMO is largely recognized as having a social nature (Hodkinson, et al., 2016; Przybylski et al., 2013) as it is linked to a need to stay connected to others, but there was little to no distinction as to any specific group of 
individuals that can lead to FOMO. This research provides a clear distinction to which group leads to most FOMO in ways that can be used by advertisers.

Another important insight provided by this dissertation is the type of experiences that influence FOMO levels the most based on the social group involved. My findings indicate that when consumers are considering missing out on an ordinary experience, they tend to feel higher levels of FOMO when their strong, rather than weak, social ties will be attending, but when the experience is extraordinary, consumer will experience high levels of FOMO regardless of the tie strength they share with the group attending. A surprising finding suggests that consumers may feel more FOMO for missing an ordinary experience with their strong social tie than missing out on an extraordinary experience. I believe this could be because consumers tend to place high value on ordinary experiences with their close friends but when the experience is more extraordinary, the tie strength between groups attending matters less and it becomes more about enjoying the rare experience itself; however, further research is required to confirm this theorizing.

While the experience literature has expressed that new experiences shared with loved ones help foster relationships and increases one's wellbeing (Bhattacharjee \& Mogilner, 2014; Schmitt, Josko Brakus, \& Zarantonello, 2015), I extend the experiences literature by identifying which experiences are the ones individuals do not want to miss out on depending on the given social group. Extraordinary experiences are valued by most individuals because they can help construct aspects of the self (Bhattacharjee \& Mogilner, 2013) and help in building one's experiential CV (Hertz, Dawson, \& Cullen, 2015), but these experiences tend to place lesser importance on the social component of sharing experiences, while ordinary experiences tend to focus more on the nurturing of relationships. 
Another meaningful finding from this dissertation is that FOMO is an anticipatory emotion that can happen prior to experiencing anticipated regret and not the other way around. This finding is important because it opens the discussion on the similarities and differences between the anticipatory emotions of FOMO and anticipated regret. While these constructs have been lightly mentioned as synonyms (Wiltermuth and Gino, 2013), the literature on FOMO seems to have widely ignored the comparisons of FOMO to anticipated regret. I found that when FOMO is replaced by anticipated regret in our serial moderated mediation model, the results are non-significant. This provides support for my theorizing that FOMO and anticipated regret are correlated constructs that work in different ways. Unlike FOMO, anticipated regret has little to do with social groups and more to do with the experience itself. While tie strength had a direct effect on FOMO, it did not have an effect on anticipated regret. I believe that regret is a broader construct that is experienced when one realizes they may have made the wrong choice, while FOMO is the fear of making a choice because one is afraid of a better option coming along. In other words, FOMO is the fear of regret and therefore as an antecedent to anticipated regret.

Finally, this is the first research to attempt to determine whether FOMO is an automatic or controlled process. In other words, I explored whether consumers tend to carefully consider FOMO when experiencing this phenomenon or do they simply feel it immediately and react to it without strong awareness to it. The results indicate that FOMO is more of an automatic process that happens spontaneously, but once one takes the time to carefully think about the experience of FOMO, the effects start to diminish, and individuals can rationalize to cope with this feeling. These results are important because when FOMO appeals are used in advertising in ways that are too obvious, participants may react to it in a more mindful way which reduces its overall effect. This 
finding is important because it helps researchers understand the underlying mechanism of this construct.

These results are important for several reasons. First, a concern with this newly established construct in the literature is addressed by empirically distinguishing FOMO from anticipated regret. Second, these results also help disassociate the current findings from previous research in which FOMO is used interchangeably with anticipated regret (Wiltermuth and Gino, 2013). Finally, it allows me to understand FOMO more accurately. When anticipated regret demonstrated significant effects, these results were not driven by the tie strength between social groups but rather the type of experience that the consumer was enjoying.

\subsection{Practical implications for marketers}

FOMO appeals have been used in advertising and in various communication channels such as television, radio, magazines, and social media. Marketers can use these findings to strengthen FOMO ad-appeals by specifically highlighting strong ties on the ad content rather than using vague group membership. Emphasizing strong social ties can also be used when creating marketing messages to communicate information about ordinary experiential purchases such as trying a new local restaurant, promoting a new special on a menu or an upcoming film. When it comes to promoting more extraordinary events, such as major concerts, marketers can tailor their message to be more about not missing out on the experience itself rather than focusing on sharing that experience with close friends.

\subsection{Limitations}

This dissertation has several limitations. Particularly when exploring a new construct that is limited in the literature, it is difficult to find theoretical support that 
directly touches on the topic of FOMO. This is the first study to link tie strength to FOMO and to propose behavior and purchase intent as a consequence of FOMO. While I explore the anticipated regret, experiential consumption, and tie strength literature, there have been no prior direct connections of these literatures to FOMO.

Another limitation is the FOMO scale that was developed by Przybylski et al. (2013) was originally developed to be an individual difference scale that was adjusted to be a circumstantial or situational scale to address the purpose of this dissertation. Although, in most cases the scale worked as intended, in the third study which included the serial moderated mediation, not all items loaded under a single component during factor analyses. This data has been reviewed by an expert in the field and given the correlations between the individual items, his conclusions were that while the results of the factor analyses were not optimal, when using experimental factor analyses the measure was OK to be used depending on the intended purpose.

The studies themselves have some limitations. In study two, the serial mediation of FOMO and anticipated regret on the relationship between tie strength and purchase intent, I had intended to control for the experience by finding an experience that was considered to be neither ordinary nor extraordinary and found through pretests that the movie theatre experience was considered to be at the midpoint in the experience scale. Yet, during the study, participants in the strong ties strength condition still perceived the neutral experience to be slightly more extraordinary than the midpoint because of the connection that they had with that social group. The weak ties strength condition did not differ from the midpoint on this respect.

There were also limitations in the behavioral study. While the intention was to find differences in FOMO levels between tie strength conditions and to see a simple mediation between tie strength to purchase intent through FOMO, I was not able to 
reach these results with the 70 participants that remained in the study. Thirty participants had to be removed from the study because one of the members of the dyad selfreported a tie strength resembling the wrong condition. This study does not take into account other potential reasons why individuals may not have reported higher levels of FOMO. For instance, previous planned activities for that given date and time which would significantly reduce FOMO.

\subsection{Future directions}

When it comes to anticipating future FOMO, the fear of missing out can become a motivational construct in that it may propel people to take action and join in a social activity due to either an intrinsic motivation to connect with others or an extrinsic motivation to avoid social punishment. In this manner, FOMO can have a positive influence on individuals by encouraging them to leave their comfort zone, meet new people and experience new things (University of Southern Queensland, 2017). However, FOMO has been more commonly connected to reduced wellbeing. The FOMO literature posits that, when a person experiences FOMO, they feel decreased enjoyment of the current, chosen event and increased expected enjoyment of the missed event (Rifkin et al., 2015). Although FOMO has been explored in various contexts particularly pertaining to how it negatively impacts students, the positive side of FOMO has not been explored. Future research will aim to address the following question: Under which conditions does FOMO lead to positive outcomes? The goal of this research is to capture the essence of this seldom explored construct in all its forms.

Given that there are so many FOMO appeals in advertisements and it is considered to be a common marketing tool, more attention should be given to how FOMO ads are perceived by consumers. Future research should explore how FOMO ads affect consumers and whether they actually are an effective marketing strategy. 
REFERENCES 
Abel, J. P., Buff, C. L., \& Burr, S. A. (2016). Social media and the fear of missing out: Scale development and assessment. Journal of Business \& Economics Research (Online), 14(1), 33.

Airbnb (2016, November). Airbnb and the rise of millennial travel [Technical Report]. Retrieved from: https://2sqy5r1jf93u30kwzc1smfqt-wpengine.netdna-ssl.com/wpcontent/uploads/ 2016/08/MillennialReport.pdf

Aron, A., Norman, C. C., Aron, E. N., \& Lewandowski, G. (2002). Shared participation in self-expanding activities: Positive effects on experienced marital quality. Understanding marriage: Developments in the study of couple interaction, 177194.

Aron, A., Norman, C. C., Aron, E. N., McKenna, C., \& Heyman, R. E. (2000). Couples' shared participation in novel and arousing activities and experienced relationship quality. Journal of personality and social psychology, 78(2), 273.

Al-Menayes, J. (2016). The Fear of Missing out Scale: Validation of the Arabic Version and Correlation with Social Media Addiction. International Journal of Applied Psychology, 6(2), 41-46.

Auverset, L., Billings, A., \& Conlin, L. (2016). Time-shifting vs. appointment viewing: the role of fear of missing out within TV consumption behaviors.

Baker, Z. G., Krieger, H., \& LeRoy, A. S. (2016). Fear of missing out: Relationships with depression, mindfulness, and physical symptoms. Translational Issues in Psychological Science, 2(3), 275.

Bargh, J. A. (1984). Automatic and conscious processing of social information. In American Psychological Association convention, 1982, Washington, DC, US; Portions of the research discussed in this chapter were presented at the aforementioned conference, and at the 1982 meetings of the Society for Experimental Social Psychology in Nashville, Indiana. Lawrence Erlbaum Associates Publishers.

Bargh, J. A. (1994). The four horsemen of automaticity: Awareness, intention, efficiency, and control in social cognition. Handbook of social cognition, 1, 1-40.

Bargh, J. A. (1989). Conditional automaticity: Varieties of automatic influence in social perception and cognition. Unintended thought, 3, 51-69.

Bargh, J. A., Chen, M., \& Burrows, L. (1996). Automaticity of social behavior: Direct effects of trait construct and stereotype activation on action. Journal of personality and social psychology, 71(2), 230.

Baumeister, R. F., DeWall, C. N., Ciarocco, N. J., \& Twenge, J. M. (2005). Social exclusion impairs self-regulation. Journal of personality and social psychology, 88(4), 589. 
Baumeister, R. F., \& Leary, M. R. (1995). The need to belong: desire for interpersonal attachments as a fundamental human motivation. Psychological bulletin, 117(3), 497.

Bell, D. E. (1982). Regret in decision making under uncertainty. Operations research, 30(5), 961-981.

Bhattacharjee, A., \& Mogilner, C. (2014). Happiness from ordinary and extraordinary experiences. Journal of Consumer Research, 41(1), 1-17.961-981.

Boothby, E. J., Smith, L. K., Clark, M. S., \& Bargh, J. A. (2017). The world looks better together: How close others enhance our visual experiences. Personal Relationships, 24(3), 694-714.

Bowlby, J. (1973). Attachment and loss: Volume II: Separation, anxiety and anger. Attachment and loss, 2, 1-429.

Bowlby, J. (2008). A secure base: Parent-child attachment and healthy human development. Basic books.

Bramel, D. (1969). Determinants of beliefs about other people. Experimental social psychology. New York: Macmillan, 77-107.

Brewer, M. B. (1988). A dual process model of impression formation. In T. K. Srull \& R. S. Wyer, Jr. (Eds.), Advances in social cognition (Vol. 1, pp. 1-36). Hillsdale, NJ: Erlbaum.

Brown, R. (1965). Social Psychology. New York: The Free Pres.

Brown, J. J., \& Reingen, P. H. (1987). Social ties and word-of-mouth referral behavior. Journal of Consumer research, 14(3), 350-362.

Bryant, F. (2003). Savoring Beliefs Inventory (SBI): A scale for measuring beliefs about savouring. Journal of mental health, 12(2), 175-196.

Buckley, K. E., Winkel, R. E., \& Leary, M. R. (2004). Reactions to acceptance and rejection: Effects of level and sequence of relational evaluation. Journal of experimental social psychology, 40(1), 14-28.

Burke, M., Marlow, C., \& Lento, T. (2010, April). Social network activity and social wellbeing. In Proceedings of the SIGCHI conference on human factors in computing systems (pp. 1909-1912). ACM.

Caprariello, P. A., \& Reis, H. T. (2013). To do, to have, or to share? Valuing experiences over material possessions depends on the involvement of others. Journal of personality and social psychology, 104(2), 199.

Carter, T. J., \& Gilovich, T. (2012). I am what I do, not what I have: The differential centrality of experiential and material purchases to the self. Journal of personality and social psychology, 102(6), 1304. 
Chartrand, T. L. (2005). The role of conscious awareness in consumer behavior. Journal of Consumer Psychology, 15(3), 203-210.

Cheever, N. A., Rosen, L. D., Carrier, L. M., \& Chavez, A. (2014). Out of sight is not out of mind: The impact of restricting wireless mobile device use on anxiety levels among low, moderate and high users. Computers in Human Behavior, 37, 290297.

Collins, L., \& Van Abeele, M. (2013). FOMO and mobiles phones: a survey study (Doctoral dissertation, Master Thesis, Tilburg University, Tilburg).

Creative Digital Agengy (n.d.). Destination marketing: millennials influence and inspiration [Blog Post]. Retrieved from: http://creativedigitalagency.com/wpcontent/uploads/Destination-Marketing-to-Millennials-Influence-Inspiration-2019Social-Media-Mobile-Travel-Tourism-Experiences-DMOs.pdf

Cresswell, J. W. (2012), Research Design: Qualitative, Quantitative, and Mixed Methods Approaches, Sage Publications, Inc., Thousand Oaks, CA.

Deci, E. L., \& Ryan, R. M. (1985). The general causality orientations scale: Selfdetermination in personality. Journal of research in personality, 19(2), 109-134.

Devine, P. G. (1989). Stereotypes and prejudice: Their automatic and controlled components. Journal of Personality and Social Psychology, 56, 5-18.

Dijksterhuis, A., Chartrand, T. L., \& Aarts, H. (2007). Effects of priming and perception on social behavior and goal pursuit.

Dijksterhuis, A., Smith, P. K., Van Baaren, R. B., \& Wigboldus, D. H. (2005). The unconscious consumer: Effects of environment on consumer behavior. Journal of consumer psychology, 15(3), 193-202.

DMV (2015). Texting and driving. Retrieved from: https://www.dmv.org/distracteddriving/ texting-and-driving.php

Dossey, L. (2014). FOMO, digital dementia, and our dangerous experiment. Explore: The Journal of Science and Healing, 10(2), 69-73.

Dunn, E. W., Aknin, L. B., \& Norton, M. I. (2008). Spending money on others promotes happiness. Science, 319(5870), 1687-1688.

Eisenberger, N. I., Lieberman, M. D., \& Williams, K. D. (2003). Does rejection hurt? An fMRI study of social exclusion. Science, 302(5643), 290-292.

Elhai, J. D., Levine, J. C., Dvorak, R. D., \& Hall, B. J. (2016). Fear of missing out, need for touch, anxiety and depression are related to problematic smartphone use. Computers in Human Behavior, 63, 509-516. 
Ellison, N. B., Steinfield, C., \& Lampe, C. (2007). The benefits of Facebook "friends:" Social capital and college students' use of online social network sites. Journal of computer-mediated communication, 12(4), 1143-1168.

Ericksen, E., \& Yancey, W. (1980). The locus of strong ties. Mimeo. Department of Sociology. Temple University, Philadelphia.

Eventbrite (n.d.). Millennials: Fueling the experience economy [Technical Report]. Retrieved from:

https://eventbrites3.s3.amazonaws.com/marketing/Millennials_Research/Gen_P R_Final.pdf

Fitness, J., \& Fletcher, G. J. (1993). Love, hate, anger, and jealousy in close relationships: a prototype and cognitive appraisal analysis. Journal of personality and social psychology, 65(5), 942.

Fox, J., \& Moreland, J. J. (2015). The dark side of social networking sites: An exploration of the relational and psychological stressors associated with Facebook use and affordances. Computers in Human Behavior, 45, 168-176.

Freedman, G., Williams, K. D., \& Beer, J. S. (2016). Softening the blow of social exclusion: The responsive theory of social exclusion. Frontiers in psychology, 7 , 1570.

Gailliot, M. T., Plant, E. A., Butz, D. A., \& Baumeister, R. F. (2007). Increasing selfregulatory strength can reduce the depleting effect of suppressing stereotypes. Personality and Social Psychology Bulletin, 33(2), 281-294.

Gilbert, E., \& Karahalios, K. (2009, April). Predicting tie strength with social media. In Proceedings of the SIGCHI conference on human factors in computing systems (pp. 211-220). ACM.

Gilovich, T., Kumar, A., \& Jampol, L. (2015). A wonderful life: Experiential consumption and the pursuit of happiness. Journal of Consumer Psychology, 25 (1), 152-165.

Gonzaga, G. C., Turner, R. A., Keltner, D., Campos, B., \& Altemus, M. (2006). Romantic love and sexual desire in close relationships. Emotion, 6(2), 163.

Granovetter, M. S. (1977). The strength of weak ties. In Social networks (pp. 347-367). Academic Press.

Granovetter, M. (1983). The strength of weak ties: A network theory revisited.

The Harbus (2004, May 10). Social Theory at HBS: McGinnis' Two FOs [Blog Post]. Retrieved from: http://www.harbus.org/2004/social-theory-at-hbs-2749/

Hato, B. (2013). Mobile Phone Checking Behavior Out of a Fear of Missing Out: Development, Psychometric Properties and Test-Retest Reliability of a C-FoMOScale ANR: 610304. Master's Thesis. 
Hay, B. (2013). From Leisure to Pleasure: Societal Trends and Their Impact on Possible Future Scenarios for UK Rural Tourism in 2050.

Herman, D. (2000). Introducing short-term brands: A new branding tool for a new consumer reality. Journal of Brand Management, 7(5), 330-340.

Herman, Dan (n.d.). Think Short. The Fear of Missing Out. Retrieved from: http://fomofearofmissingout.com/short-term-brands

Hetz, P. R., Dawson, C. L., \& Cullen, T. A. (2015). Social media use and the fear of missing out (FoMO) while studying abroad. Journal of Research on Technology in Education, 47(4), 259-272.

Hodkinson, C. (2016). 'Fear of Missing Out'(FOMO) marketing appeals: A conceptual model. Journal of Marketing Communications, 1-24.

Holm, M. R., Lugosi, P., Croes, R. R., \& Torres, E. N. (2017). Risk-tourism, risk-taking and subjective well-being: A review and synthesis. Tourism Management, 63, 115-122.

Howell, R. T., \& Hill, G. (2009). The mediators of experiential purchases: Determining the impact of psychological needs satisfaction and social comparison. The Journal of Positive Psychology, 4(6), 511-522.

JWT Worldwide (2011, May 4). FOMO: JWT Explores Fear of Missing Out Phenomenon [Blog Post]. Retrieved from:

www.jwt.com/fomojwtexploresfearofmissingoutphenomenon/

Keinan, A., \& Kivetz, R. (2008). Productivity mindset and the consumption of collectable experiences, in NA - Advances in Consumer Research Volume 35, Eds. Angela Y. Lee and Dilip Soman, Duluth, MN : Association for Consumer Research, 101105.

Kim, W., Jeong, O. R., \& Lee, S. W. (2010). On social Web sites. Information systems, 35(2), 215-236.

LaBerge, D., \& Samuels, S. J. (1974). Toward a theory of automatic information processing in reading. Cognitive psychology, 6(2), 293-323.

Lai, C., Altavilla, D., Ronconi, A., \& Aceto, P. (2016). Fear of missing out (FOMO) is associated with activation of the right middle temporal gyrus during inclusion social cue. Computers in Human Behavior, 61, 516-521.

Lampe, C. A., Ellison, N., \& Steinfield, C. (2007, April). A familiar face (book): profile elements as signals in an online social network. In Proceedings of the SIGCHI conference on Human factors in computing systems (pp. 435-444). ACM.

Lazarus, R. S. (1991). Cognition and motivation in emotion. American psychologist, 46(4), 352. 
Laumann, E. (1968). Interlocking and Radial Friendship Networks: A Crosssectional Analysis. Mimeographed. Ann Arbor: University of Michigan.

Lee, J., \& Shrum, L. J. (2012). Conspicuous consumption versus charitable behavior in response to social exclusion: A differential needs explanation. Journal of Consumer Research, 39(3), 530-544.

Lin, N., Ensel, W. M., \& Vaughn, J. C. (1981). Social resources and strength of ties: Structural factors in occupational status attainment. American sociological review, 393-405.

Loomes, G., Starmer, C., \& Sugden, R. (1992). Are preferences monotonic? Testing some predictions of regret theory. Economica, 17-33.

Luce, R. D., \& Raiffa, H. (1957). Games and decisions: Introduction and critical surveys. New York: Wiley.

Marsden, P. V. (1988). Homogeneity in confiding relations. Social networks, 10(1), 5776.

Marsden, P. V., \& Campbell, K. E. (1984). Measuring tie strength. Social forces, 63(2), 482-501.

Mead, N. L., Baumeister, R. F., Stillman, T. F., Rawn, C. D., \& Vohs, K. D. (2011). Social exclusion causes people to spend and consume strategically in the service of affiliation. Journal of Consumer Research, 37(5), 902-919.

Mitchell, T. R., Thompson, L., Peterson, E., \& Cronk, R. (1997). Temporal adjustments in the evaluation of events: The "rosy view". Journal of experimental social psychology, 33(4), 421-448.

Murray, S. O., Rankin, J. H., \& Magill, D. W. (1981). Strong ties and job information. Sociology of Work and Occupations, 8(1), 119-136.

Nadkarni, A., \& Hofmann, S. G. (2012). Why do people use Facebook? Personality and individual differences, 52(3), 243-249.

Nelson, L. D., Meyvis, T., \& Galak, J. (2009). Enhancing the television-viewing experience through commercial interruptions. Journal of Consumer Research, 36(2), 160-172.

Newcomb, T. M. (1961). The acquaintance process as a prototype of human interaction.

Parducci, A. (1995). Happiness, pleasure, and judgment: The contextual theory and its applications. Lawrence Erlbaum Associates, Inc.

Perdue, C. W , \& Gurtman, M. B. (1990). Evidence for the automaticity of ageism. Journal of Experimental Social Psychology, 26, 199 - 216. 
Pesce, N. L. (2019, June 6). The average U.S. adult will spend three hours and 43 minutes a day on mobile devices this year [Blog Post]. Market Watch. Retrieved from: https://www.marketwatch.com/story/for-the-first-time-ever-americans-willspend-more-time-on-mobile-devices-than-watching-tv-2019-06-05.

Posner, M. I., Snyder, C., \& Solso, R. L. (1975). Information processing and cognition: The Loyola symposium.

Pratto, F., \& Bargh, J. A. (1991). Stereotyping based on apparently individuating information: Trait and global components of sex stereotypes under attention overload. Journal of Experimental Social Psychology, 27(1), 26-47.

Preacher, K. J., \& Hayes, A. F. (2008). Asymptotic and resampling strategies for assessing and comparing indirect effects in multiple mediator models. Behavior research methods, 40(3), 879-891.

Preacher, K. J., Rucker, D. D., \& Hayes, A. F. (2007). Addressing moderated mediation hypotheses: Theory, methods, and prescriptions. Multivariate behavioral research, 42(1), 185-227.

Przybylski, A. K., Murayama, K., DeHaan, C. R., \& Gladwell, V. (2013). Motivational, emotional, and behavioral correlates of fear of missing out. Computers in Human Behavior, 29(4), 1841-1848.

Quoidbach, J., Berry, E. V., Hansenne, M., \& Mikolajczak, M. (2010). Positive emotion regulation and well-being: Comparing the impact of eight savoring and dampening strategies. Personality and individual differences, 49(5), 368-373.

Rifkin, J., Chan, C., \& Kahn, B. (2015). Fomo: How the Fear of Missing Out Leads to Missing Out. NA-Advances in Consumer Research Volume 43.

Riordan, B. C., Flett, J. A., Hunter, J. A., Scarf, D., \& Conner, T. S. (2015). Fear of missing out (FoMO): The relationship between FoMO, alcohol use, and alcoholrelated consequences in college students. Ann Neurosc Psychol, 2.

Ritov, I. (1996). Probability of regret: Anticipation of uncertainty resolution in choice. Organizational Behavior and Human Decision Processes, 66(2), 228-236.

Ryan, R. M., \& Deci, E. L. (2000). Intrinsic and extrinsic motivations: Classic definitions and new directions. Contemporary educational psychology, 25(1), 54-67.

Sandberg, T., \& Conner, M. (2008). Anticipated regret as an additional predictor in the theory of planned behaviour: A meta-analysis. British Journal of Social Psychology, 47(4), 589-606.

Schmitt, B., Joško Brakus, J., \& Zarantonello, L. (2015). From experiential psychology to consumer experience. Journal of Consumer Psychology, 25(1), 166-171. 
Seidman, G. (2013). Self-presentation and belonging on Facebook: How personality influences social media use and motivations. Personality and Individual Differences, 54(3), 402-407.

Shani, Y., Danziger, S., \& Zeelenberg, M. (2015). Choosing between options associated with past and future regret. Organizational Behavior and Human Decision Processes, 126, 107-114.

Sheeran, P., \& Orbell, S. (1999). Augmenting the theory of planned behavior: Roles for anticipated regret and descriptive norms. Journal of Applied Social Psychology, 29(10), 2107-2142.

Shiffrin, R. M., \& Schneider, W. (1977). Controlled and automatic human information processing: II. Perceptual learning, automatic attending and a general theory. Psychological review, 84(2), 127.

South China Morning Post (2019, January 22). Taiwan's 'Bikini Climber' social media star Gigi Wu dies after ravine fall in Yushan national park [Blog Post]. Retrieved from: https://www.scmp.com/ sport/outdoor/extremesports/article/2183119/taiwans-bikini-climber-social-media-star-gigi-wu-dies

The Sattvic Life (2015, January 19). From FOMO to FOMA to Fearless [Blog Post]. Retrieved from: https://thesattviclife.com/2015/01/19/from-fomo-to-foma-tofearless/

Torres, E. N. (2016). Guest interactions and the formation of memorable experiences: an ethnography. International Journal of Contemporary Hospitality Management, 28(10), 2132-2155.

Tsiros, M., \& Mittal, V. (2000). Regret: A model of its antecedents and consequences in consumer decision making. Journal of Consumer Research, 26(4), 401-417.

Tversky, A., \& Griffin, D. (1991). 12 Endowment and Contrast in Judgments of WellBeing. Strategy and choice, 297.

Twenge, J. M., Baumeister, R. F., DeWall, C. N., Ciarocco, N. J., \& Bartels, J. M. (2007). Social exclusion decreases prosocial behavior. Journal of personality and social psychology, 92(1), 56.

Twenge, J. M., Baumeister, R. F., Tice, D. M., \& Stucke, T. S. (2001). If you can't join them, beat them: Effects of social exclusion on aggressive behavior. Journal of personality and social psychology, 81(6), 1058.

Twenge, J. M., Catanese, K. R., \& Baumeister, R. F. (2002). Social exclusion causes self-defeating behavior. Journal of personality and social psychology, 83(3), 606.

University of Southern Queensland (2017). Don't Fight the FOMO [Slide Share presentation]. Retrieved from https://social.usq.edu.au/study-tips/2017/02/dontfight-the-fomo 
Van Boven, L. (2005). Experientialism, materialism, and the pursuit of happiness. Review of general psychology, 9(2), 132.

Van Boven, L., \& Gilovich, T. (2003). To do or to have? That is the question. Journal of personality and social psychology, 85(6), 1193.

Van Boven, L., \& Gilovich, T. (2004). The social costs of materialism. Unpublished manuscript, University of Colorado, Boulder.

Vaughn, Jessica (2012, March 28). Study: Priya Parker, researcher and founder of Thrive Labs [Blog Post]. JWT Intelligence. Retrieved from:

https://www.jwtintelligence.com/2012/03/ qa-priya-parker-researcher-andfounder-of-thrive-labs/

Voboril, K. (2010, February 8). FOMO: The Fear of Missing Out [Blog Post]. Bloomberg. Retrieved from: http://www.bloomberg.com/news/articles/2010-02-08/fomo-thefear-of-missing-out.

Vu, H. Q., Li, G., Law, R., \& Zhang, Y. (2018). Tourist activity analysis by leveraging mobile social media data. Journal of travel research, 57(7), 883-898.

Weiss, R. S. (1973). Loneliness: The experience of emotional and social isolation.

Wiltermuth, S. S., \& Gino, F. (2013). "I'Il have one of each": How separating rewards into (meaningless) categories increases motivation. Journal of personality and social psychology, 104(1), 1.

Winnick, M. (2016, June 16). Putting a Finger on Our Phone Obsession [Blog Post]. Retrieved from: https://blog.dscout.com/mobile-touches

Wirtz, J., \& Chew, P. (2002). The effects of incentives, deal proneness, satisfaction and tie strength on word-of-mouth behaviour. International journal of service industry management, 13(2), 141-162.

Wortham, J. (2011). How Social Media Can Induce Feelings of 'Missing Out' [Blog Post]. Nytimes.com. Retrieved 13 October 2017, from http://www.nytimes.com/2011/04/10/ business/10ping.html?_r=0

Zeelenberg, M. (1999). Anticipated regret, expected feedback and behavioral decision making. Journal of behavioral decision making, 12(2), 93.

Zeelenberg, M., \& Beattie, J. (1997). Consequences of regret aversion 2: Additional evidence for effects of feedback on decision making. Organizational Behavior and Human Decision Processes, 72(1), 63-78.

Zeelenberg, M., \& Pieters, R. (2007). A theory of regret regulation 1.0. Journal of Consumer psychology, 17(1), 3-18.

Zeelenberg, M., Van Dijk, W. W., Manstead, A., \& der Pligt, J. (1998). The experience of regret and disappointment. Cognition \& Emotion, 12(2), 221-230. 
Zeelenberg, M., Van Dijk, W. W., Manstead, A. S., \& der Pligt, J. (2000). On bad decisions and disconfirmed expectancies: The psychology of regret and disappointment. Cognition \& Emotion, 14(4), 521-541. 
APPENDIX 


\section{APPENDIX A}

Frequency word cloud for focus group study

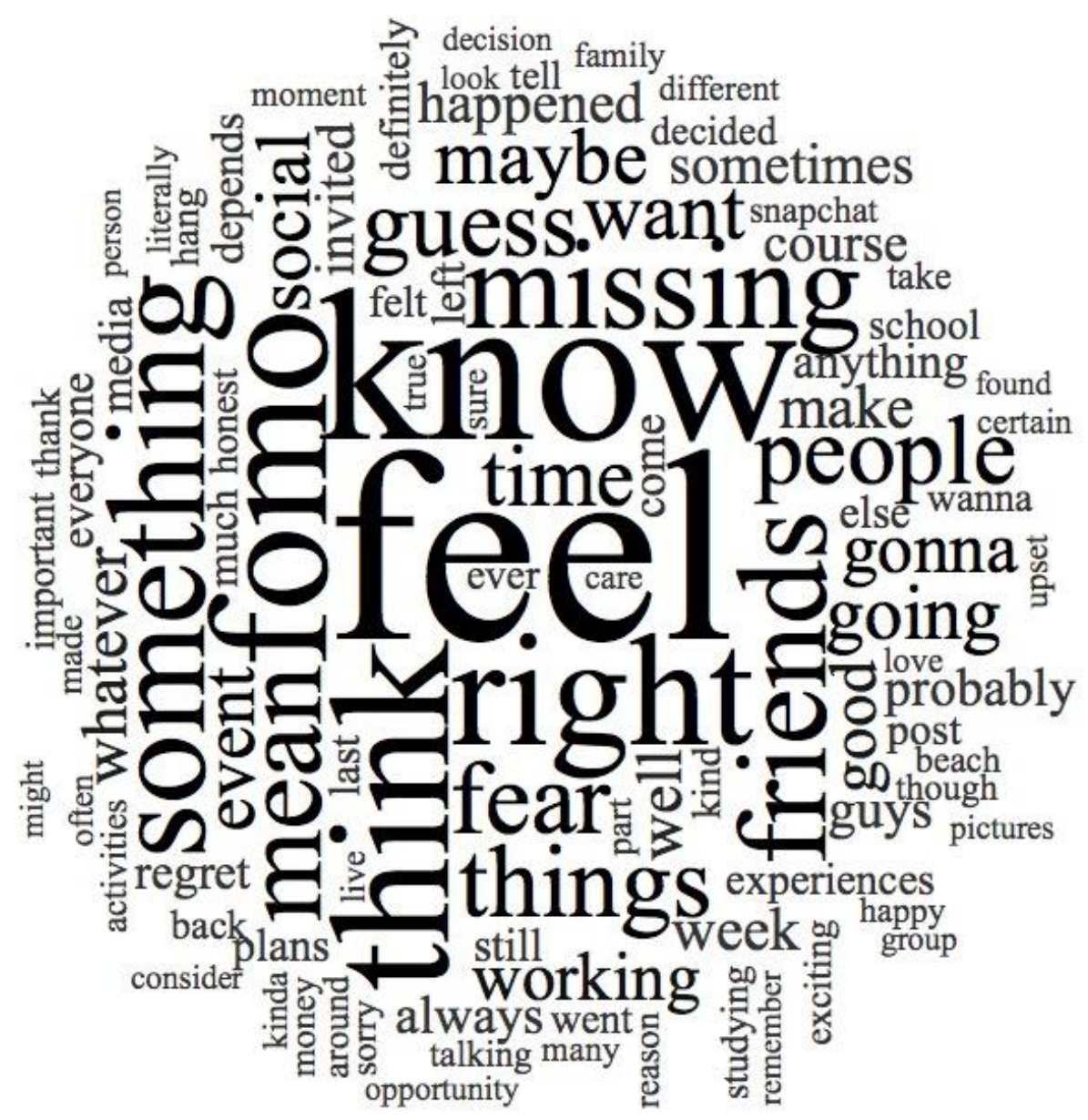




\section{APPENDIX B}

Adjusted tie-strength measure (Mittal, Huppertz, and Khare (2008)

How close, would you say, you are to the group of people going to this event? $(1=$ Not at all close, $7=$ Very close $)$

How strong, would you say, is your tie to the group of people going to this event?

( $1=$ Very weak, 7 = very strong $)$

How familiar do you feel with the group of people going to this event?

( $1=$ not at all familiar, $7=$ very familiar $)$

Please indicate the level of closeness you feel towards the group of people going to this event.

$(1=$ not at all close, $7=$ very close $)$ 


\section{APPENDIX C}

Adjusted FOMO measure (Przybylski, Murayama, DeHaan, \& Gladwell, 2013)

Please think about the earlier scenario and the group of people going, then indicate the extent to which each of the following statements describe your feelings right now:

$1=$ Strongly disagree, 7 = Strongly agree

1. I would fear that those going would have more rewarding experiences than me.

2. I would be worried knowing that those going would be having fun without me.

3. I would get anxious not knowing what they are up to.

4. It is important that I understand their "inside jokes" related to this event.

5. I would likely spend some time trying to keep up with what is going on.

6. It would bother me to miss out on this particular opportunity to meet up with those that are going. 


\section{APPENDIX D}

Adjusted anticipated regret measure (Zeelenberg, van Dijk, Manstead \& der Plight, 1998)

For the following items, please indicate how you would feel if you did not attend this event.

1 = Strongly disagree, 7 = Strongly agree

1. I would feel a sinking feeling.

2. I would think about it quite a bit.

3. I would wonder whether I had made a mistake.

4. I would think about it as a lost opportunity.

5. I would want to do things differently.

6. I would want to change the situation. 


\section{APPENDIX E}

Image displayed in study 4

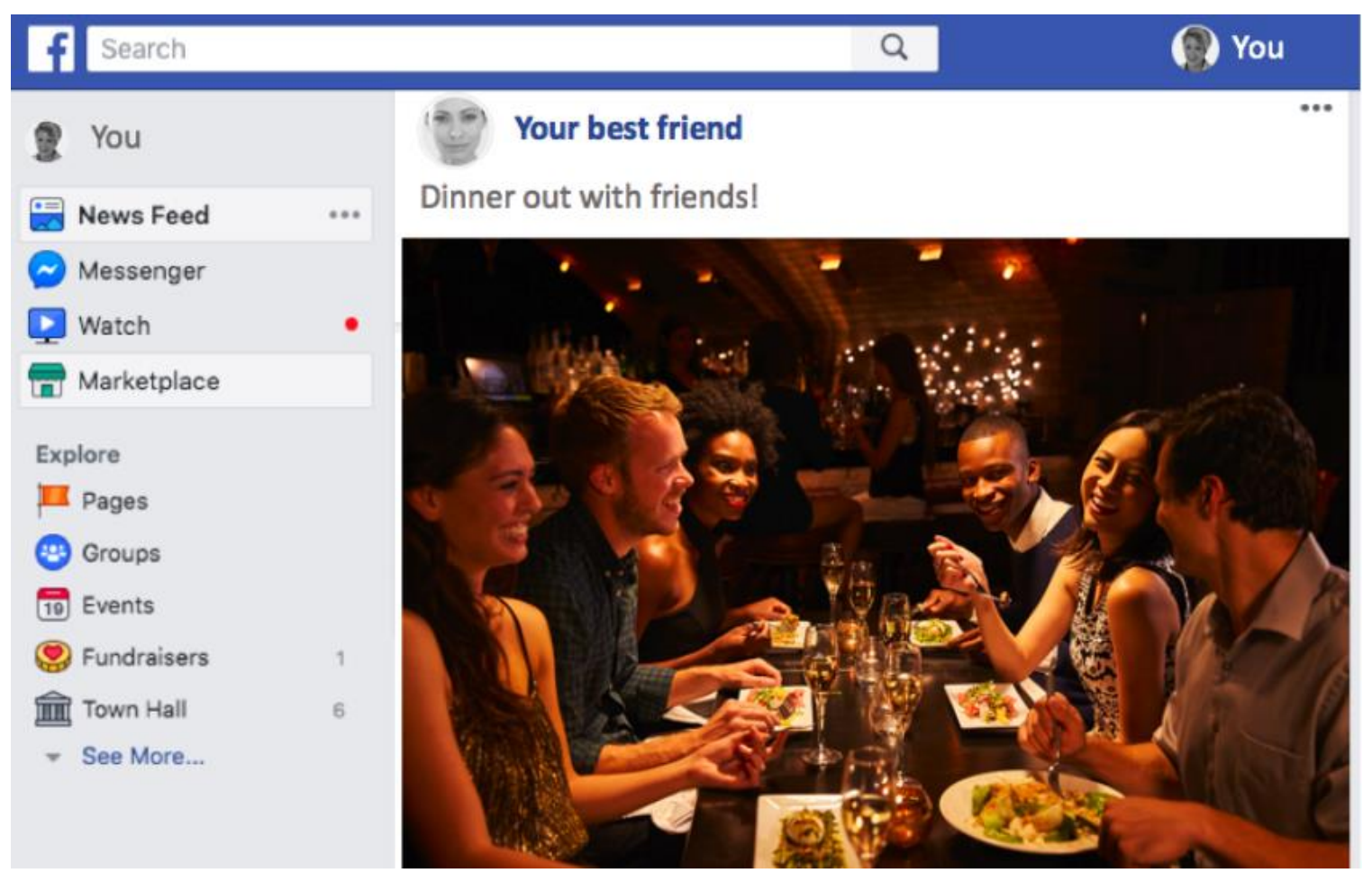




\section{APPENDIX G}

Movie stimuli for behavioral study (study 5)

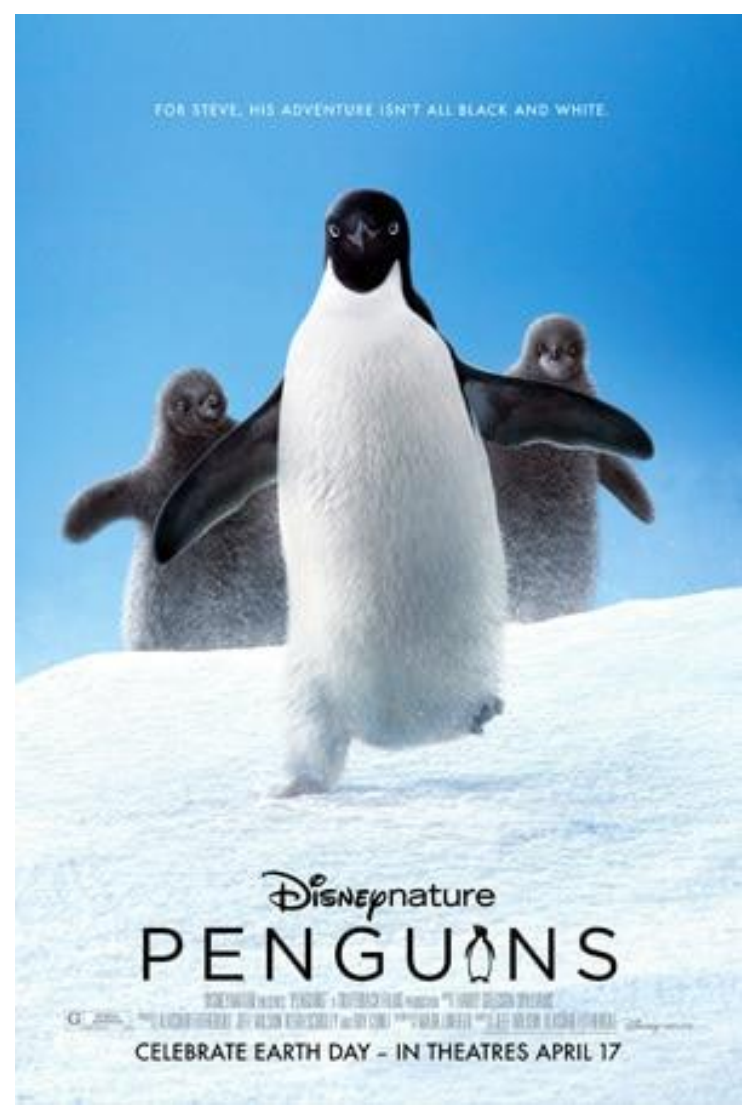

Disneynature's all-new feature film "Penguins" is a coming-of-age story about an Adélie penguin named Steve who joins millions of fellow males in the icy Antarctic spring on a quest to build a suitable nest, find a life partner and start a family. None of it comes easily for him, especially considering he's targeted by everything from killer whales to leopard seals, who unapologetically threaten his happily ever after.

Directors: Alastair Fothergill, Jeff Wilson

Star: Ed Helms

Genre: Documentary 
VITA 


\title{
VITA
}

\section{MICHELLE VAN SOLT}

\section{EDUCATION}

\author{
2019 PH.D., Marketing \\ Florida International University \\ 2015 M.I.B., Master of International Business \\ Florida International University \\ $2011 \quad$ B.A.S., Marketing \\ Florida State University
}

\section{ACADEMIC PUBLICATIONS AND PRESENTATIONS}

Tsalikis, J., Seaton, B., Shepherd, P. L., \& van Solt, M. (2018). The impact of the US government policies on consumer perceptions of business ethical behavior. Society and Business Review.

Tsalikis, J., \& van Solt, M. (2019). Business ethics index: the impact of political affiliation. Social Responsibility Journal.

Tsalikis, J. \& van Solt, M. (2019). Measuring consumers' perceptions of business ethicality on price, product, and service domains. Cross Cultural \& Strategic Management.

"Pleasure and Pain: How Anticipated Pleasure Compensates for Pain of Payment," Mt. Pleasant, SC, Association of Marketing Theory and Practice, March 2019 (with Gouveia, Patricia T., Miniard, Paul W., Michelle van Solt, and Alexandra Rodriguez-Aguirre)

"Pleasure and Pain: How Anticipated Pleasure Compensates for Pain of Payment," Miami, FL, Graduate School Appreciation Week at Florida International University, March 2019 (with Gouveia, Patricia T., Miniard, Paul W., Michelle van Solt, and Alexandra Rodriguez-Aguirre)

"\#FOMO: How the Fear of Missing Out Drives Consumer Experiential Purchase Decisions," Dallas, TX, Association for Consumer Research, October 2018 (with Jessica Rixom and Kimberly A. Taylor in a working paper session)

"\#FOMO: How the Fear of Missing Out Drives Consumer Experiential Purchase Decisions," Vedra Beach, FL, Association of Marketing Theory and Practice Conference, March 2018 (with Jessica Rixom and Kimberly A. Taylor in a competitive paper session)

"\#FOMO: How the Fear of Missing Out Drives Consumer Experiential Purchase Decisions," Miami, FL, Graduate School Appreciation Week at Florida International University, March 2018 (with Jessica Rixom and Kimberly A. Taylor in a competitive paper session) 